\title{
Hillel de Vérone, traducteur et annotateur du Livre des causes en hébreu, en Italie à la fin du XIII ${ }^{\mathbf{e}}$ siècle
}

\author{
Jean-Pierre Rothschild \\ CNRS, IRHT-PSL, École pratique des hautes études, Paris
}

Le Liber de causis connut un notable succès en hébreu, en Italie, entre le dernier quart du XIII ${ }^{\mathrm{e}}$ siècle et le premier quart du XIV siècle. Sur la base de la traduction de l' arabe en latin par Gérard de Crémone (entre 1167 et 1187) il fut traduit 1) par Hillel de Vérone, après 1272 ;2) par Juda Romano pendant le premier quart du XIV e siècle; 3 ) par 'Eli Habilio ( $f$ l. ca. 1470); en outre il l' avait été, à partir de l'arabe, par l'Espagnol Zerahiyah Ḥen, en Italie encore, dans les années 1280; enfin, le manuscrit de Paris, BN(F), hébreu 706 contient une autre traduction, anonyme, indépendante des précédentes, limitée aux «théorèmes» sans les « démonstrations » ou développements.

Les raisons de ce succès sont malaisées à assigner au-delà de la simple vraisemblance: l' existence de quelques cercles désireux et en mesure d'accéder à des textes scolastiques latins; l'intérêt privilégié, dans ces cercles, pour la traduction de textes à succès de la scolastique chrétienne, surtout lorsqu'ils étaient brefs et pouvaient prendre la forme d'un catéchisme; l'émulation à l'intérieur d'un même milieu puis, peut-être, dans le cas de Habilio, le désir de se poser comme le spécialiste du domaine en substituant ses traductions à celles qui existaient, ou de se faire leur réviseur puriste à la manière des nouveaux traducteurs humanistes; l'intérêt particulier de disposer d'un cadre de pensée ou d' une autorité pour se représenter les relations des hautes entités de la métaphysique, comblant ainsi un vide laissé par Aristote, et en accord avec le monothéisme ${ }^{1}$; l' intérêt pour une doctrine qui pouvait résonner à la fois avec

1 Cf. D’Ancona 1992a [D’Ancona 1995, p. 217]: «les thèses incontestablement néoplatoniciennes des lemmes ont été conçues par ces auteurs comme étant le véritable sommet de la métaphysique d'Aristote [...] une continuité réelle subsiste [à leurs yeux] entre la métaphysique aristotélicienne et ce qui était envisagé comme son dernier achèvement: la doctrine des premiers principes et des substances séparées présentée dans le De causis [...] On a déjà remarqué que le sujet lui-même du traité De causis a été soudé au principe fondamental de l'épistémologie aristotélicienne, la définition de la connaissance véritable comme connaissance des causes »; et toute la suite de l' article montre comment les premiers commentateurs latins ont identifié dans la doctrine des éléments aristotéliciens. D’Ancona 1992b [D’Ancona 1995, p. 239]:

(C) KONINKLIJKE BRILL NV, LEIDEN, THE NETHERLANDS, 2021 | DOI:10.1163/9789004440685_019

This is an open access chapter distributed under the terms of the CC BY 4. license. 
les formules et les représentations spontanées de la piété la plus traditionnelle (la Cause première plus présente et agissante que les causes prochaines de la proposition 1 évoque irrésistiblement le «Notre Père, notre Roi», très proche et très lointain tout ensemble, de la liturgie des Jours redoutables aussi bien que toute la problématique de la providence générale ou particulière) et s' accorder, dans des milieux plus savants, avec les métaphores de l'épanchement dont Maïmonide, fort cultivé dans le premier milieu italien de ces traductions ${ }^{2}$, est prodigue; ces métaphores sont familières aussi aux auteurs kabbalistes (l'un d' eux, Abraham Abulafia, fut un élève de Hillel de Vérone) et le Liber de causis, en même temps que cette convergence, pouvait apporter de quoi échapper aux risques de polythéisme ou du moins d'atteinte à l'unité et à la toute-puissance divine que pouvait comporter leur doctrine au moins aux yeux des philosophes de formation ${ }^{3}$. Un annotateur critique des extraits traduits par Juda Romano du commentaire de Thomas d'Aquin au Liber de causis, Moïse b. Sabbataï (fl. v. 1340), utilise d' abondance le Liber pour combattre la théorie des sefirot, tant dans sa version ancienne que dans la nouvelle, introduite par Menahem de Recanati ${ }^{4}$.

Ces motifs de vraisemblance ou ces justifications a posteriori gagneront à être éclairés par les éléments de commentaire, gloses et notes, introduits selon toute vraisemblance par l'un des traducteurs, Hillel de Vérone, dans l'unique manuscrit de sa propre traduction partielle. Déjà partiellement éditées ${ }^{5}$, ces notes n' ont jamais été analysées. Nous les (ré)éditons en fin d'article, à partir du manuscrit unique, et nous en donnons pour la première fois une traduction et un commentaire.

«Les progrès des recherches démontrent en effet que, lorsque des interprètes médiévaux, tels Albert le Grand ou Gilles de Rome, conçoivent ce traité comme un «quinzième livre» à rattacher à la Métaphysique d' Aristote, ils sont moins naïfs qu' on pourrait le croire sans une analyse détaillée de la doctrine du Liber de causis. Résultat du projet entamé par l' hellénisme arabe naissant, cet ouvrage se présente en effet aux lecteurs du XIII ${ }^{\mathrm{e}}$ siècle comme un traité de théologie philosophique ad mentem Aristotelis, qui reconnaît un seul Dieu créateur et provident, et présente une version de la doctrine néoplatonicienne du premier principe qui était déjà familière, dès la tradition des œuvres de Denys».

2 Sur lequel voir l' article toujours fondamental de Sermoneta (1965).

3 Ces motivations possibles ont déjà été énumérées dans Rothschild 2013b; Rothschild 2015, p. 29-30.

4 V. Rothschild 2018, p. 10-15, p. 136-163 et, pour le texte hébreu correspondant, p. 199-221.

5 Par Moritz Steinschneider dans Hillel de Vérone, Sefer tagmuley ha-nefeš, éd. S.Z.H. Halberstamm, f. מאrv, qui indique en tête qu'il ne s' agit que de notes prises autrefois en vue de son ouvrage sur les traducteurs, qu'il n'avait pas l'intention de publier et qui auraient mérité d'être vérifiées sur le manuscrit. 
1) Le ms. Oxford, Bodleian Library, Michael 335 [(olim 82) = catalogue Neubauer $1318^{6}$, f. 75-81v (le commentaire s'étend jusqu' au f. $82^{7}$ ) (I.M.M.H. 22132)] est l'unique témoin d'une traduction en hébreu, partielle et commentée, du Livre des causes. L' écriture, de style ashkenaze, serait datable au milieu du $\mathrm{Xv}^{\mathrm{e}}$ s. ${ }^{8}$, mais l'attribution des notes critiques à un certain Hillel a fait attribuer le tout à Hillel de Vérone, actif en Italie vers la fin du XIII ${ }^{\mathrm{e}}$ s.: ainsi, en dépit du caractère de copie de travail de ce manuscrit à la présentation très modeste et peu soignée, est-on loin d' avoir affaire à un autographe. Le recueil, dû à différentes mains du milieu du Xve s. ${ }^{9}$, se caractérise par la forte présence d' écrits de logique (f. 1-35, 43-45, 55-62) ou de recueils de définitions (Livre des définitions d' Isaac Israéli, f. 45v-54; lexique, f. 63-66; à partir du Liber de causis, il s' agit davantage d'ouvrages philosophiques ou exégétiques (f. 82-85v: petit traité de l'âme, anonyme, et notes de psychologie discontinues; f. 87-101, Kalonymos b. Kalonymos, Le Serviteur de Moïse (Mešareth Mošeh), défense de la théorie maïmonidienne de la providence; f. 102-107, Abraham bar Hiyya, Pensée de l'âme (Higgayon ha-nefeš), traité de morale philosophique; f. 108-122, Abraham Ibn Ezra, Livre du Nom (Sefer ha-Šem) et commentaire du même).

2) La structure du texte est la suivante: le traducteur distingue, dans son prologue, puis le copiste sépare physiquement dans la copie, les propositions ( $h a q$ damot) et leur «commentaire» (peyruš), distingué des propositions par un passage à la ligne et la mention: «le commentateur dit» (amar ha-mefareš). La traduction est incomplète car il manque certains «commentaires», ou développements ${ }^{10}$, omis ou abrégés, explicitement ou non, presque systématiquement à partir de la prop. $2^{11}$. Les propositions, initialement non numérotées, sont au nombre de trente et une. Une main moderne les a numérotées en chiffres hébreux, jusqu'à trente-deux, en comptant pour deux (4-5) la quatrième proposition, non scindée dans le texte, et en comptant la proposition $8(9)$ bien qu' elle soit réduite à presque rien ( $\$ 8$ o de l'éd. Pattin) et ajoutée sans

6 Neubauer 1886, col. 465-467; description du contenu plus complète dans le catalogue en ligne de l'Institute of Microfilms of Hebrew Manuscripts de Jérusalem.

7 D' après Zonta 1996, p. 228, n. 12, le texte se termine à 85 v, mais il semble bien s' agir d' autre chose dès le f. 82 ; nous suivons la foliotation inscrite sur le manuscrit.

8 May, Beit-Arié 1994, p. 219.

$9 \quad$ May, Beit-Arié 1994, p. 219.

10 Que nous appellerons désormais «développements», pour éviter la confusion avec les commentaires latins allégués et les commentaires mêmes de Hillel, que nous nommerons, pour la même raison, de préférence, «notes».

11 Manquent les développements des prop. 9, 12, 16, 20-23, 28-31, ceux des prop. 25-27 et 32 sont fortement abrégés. 
solution de continuité à la fin de la proposition $7(8)$ (en l' absence de proximité particulière entre elles, cette réduction de la prop. 8(9) ne paraît pas résulter d'un principe délibéré [comme il arrive pour l'omission de développements que Hillel déclare oiseux] mais de quelque accident textuel); les prop. 9(10) à 13(14) ont reçu les numéros 10, 12, 24, 11 et 13, le no 24 étant placé entre les numéros 23 et 25 . Le traducteur ou quelque intervenant insère des gloses copiées à l' intérieur du texte sans discontinuité12 ; des notes critiques figurent à partir de la prop. 6(7), introduites par les mots: «Hillel dit» (amar Hillel), dans l'espace du texte copié. Il n' est pas sûr qu' on doive attribuer au même intervenant deux notes critiques regardant la prop. 1 et deux notes explicatives portant respectivement sur des points du texte des propositions 2 et 3 : elles se trouvent en effet en marge, quoique d'une main qui ne distingue pas à première vue de celle du copiste principal, et elles ne sont pas introduites par amar Hillel mais par des formules courantes pour des interventions de cette nature, teymah («c'est étonnant») et qašizah («il y a là une difficulté») pour les deux objections, peyruš («explication») pour les deux explications. En outre, à la prop. 4, trois fois $(\S \S 45,49,53)$ et à la prop. $6(7)$, $§ 70$, la mention dans le texte ou en marge d' autres leçons (גירסה [אחרת] = גי', ג'וא, ou en araméen גרסא אחרא, «[autre] leçon») suppose une révision, apparemment limitée à cette proposition, qu'on n'a pas de raison d' attribuer à un autre que le premier traducteur. Enfin il faut noter que le texte prend fin, après une longue note sur la prop. 32, au milieu du f. 82r, immédiatement suivi d' un petit traité de l'âme ou d' une suite de notes discontinues à dominante psychologique dont la première a trait à la perfection de l'âme ${ }^{13}$, qui s' étendent jusqu' au f. 85 , où apparaissent les noms de Maïmonide et d' Aristote et, cités par «Hillel», des titres de recueils midra-

12 Elles figurent entre accolades dans l'édition de la traduction elle-même, Rothschild 2013c.

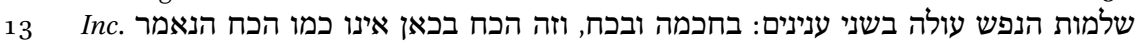

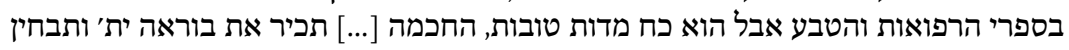
בסין sance; mais la puissance dont on parle ici n' est pas comme celle dont il est question dans les livres de médecine et de [science] naturelle», etc.; ce début parait sur quelques lignes comme une paraphrase de la Logique d' al-Ghazzâlî (nous citons la traduction latine de Dominicus Gundissalinus: Logica et philosophia, f. a2v: Perfectio anime constat in duobus: munditia scilicet et ornatu. Munditia vero anime est vt expurgetur a sordidibus moribus et suspendatur a phantasiis turpibus. Ornatus vero eius est ut depingatur in ea certitudo veritatis ita ut reuelentur ei veritates diuine [...] in qua non fit error nec occultatio) mais la suite diverge. - L'ensemble de ce texte a été publié sans annotation par Steinschneider dans Halberstamm, éd. cit., à la suite immédiate de ses notes sur la traduction annotée du Liber de causis, f. מבבvvv, à partir, semble-t-il, d'une transcription faite par un autre. 
chiques, avec une note Amar R. Ellul (f. 83v) dans laquelle Steinschneider a cru voir une confusion italienne avec le nom de Hillel et une note Amar Hillel au f. 84 .

3) Il est temps de considérer de plus près la question de l'auteur de la traduction, des gloses et des notes: c' est Moritz Steinschneider qui paraît avoir posé, sans s'en expliquer, l' identité du traducteur, du commentateur et de Hillel de Vérone ${ }^{14}$, suivi sur ce point par Adolf Neubauer, l' auteur du catalogue des manuscrits hébreux de la Bibliothèque Bodléienne.

Il peut être utile d' argumenter quelque peu cette attribution. Le nom de Hillel (une fois, Hillel b. Samuel, identité du patronyme qui a sans doute servi à fonder l'attribution) n' apparaît qu' en tête du commentaire critique des propositions, à partir de la prop. 7, f. 77 r jusqu'à la fin. Le début des notes qui suivent les prop. $7^{15}, 15$ (numérotée $\left.14^{16}\right), 16\left(n^{0} 15^{17}\right)$ renforce la probabilité que le glossateur (en tout cas celui qui s'exprime sous le nom de Hillel) soit le même que le traducteur: il indique n' avoir pas «écrit» (lo' kathabhti) certains éléments du développement originel des propositions qui lui semblaient inutiles; toutefois il reste possible que le glossateur n' ait seulement pas «copié», à partir de la traduction hébraïque déjà existante et plus complète, les éléments dont il parle. Nulle citation du De causis, explicite ou non, n'a été relevée par les éditeurs du grand ouvrage de Hillel de Vérone, écrit à la fin de sa vie, les Rétributions de l'âme (Sefer tagmuley ha-nefeš) ${ }^{18}$; du moins peut-on faire valoir que leur auteur utilise l' assez rare Sefer ha-hathaloth d' al-Fārābīị , référence de prédilection du Hillel, glossateur du De causis; ensuite, que le glossateur manifeste un intérêt pour des implications doctrinales regardant la médecine, et que Hillel est médecin (mais c' est le cas de bien des philosophes juifs). Au total, une

14 Steinschneider 1863, p. 110-114 (111), puis Steinschneider 1893 [1956] p. 262-263, renvoyant

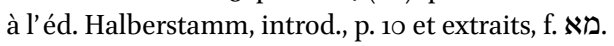

אמר הלל בן החסיד ר' שמואל זצוק״ל המפרש האריך הנה בדברים יתרים בלתי צריכים ולכן 15 את כת כ' C'est la seule fois où apparaît le patronyme de ben Samuel, qui ne fournit qu' une probabilité d' identification avec l' auteur des Tagmuley ha-nefeš, une homonymie étant toujours possible et ces noms, très courants.

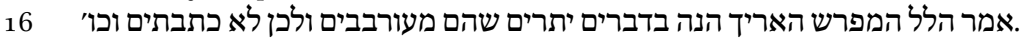

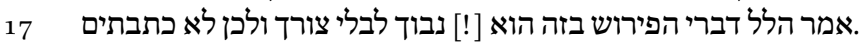

18 Steinschneider en relevait une, qui militait selon lui en sens inverse, trouvant invraisemblable que Hillel ne se soit pas servi de sa propre traduction, si elle avait déjà été écrite; mais les éditeurs suivants, Sermoneta et Schwartz, n' ont dit mot de cette référence.

19 Hillel de Vérone, Sefer Tagmulé ha-nefesh (éd. Sermoneta), p. 240 et index des textes allégués dans le commentaire, p. 268; Über die Vollendung der Seele, p. 3 o1. 
constellation d'arguments faibles, pour et contre, mais en voici un bien plus fort:l'identité du traducteur avec Hillel de Vérone semble garantie parl'emploi (prop. 1) d'un mot très rare, șidduq ${ }^{20}$, plusieurs fois employé dans les Rétributions de l'âme; or si le traducteur lui-même est Hillel de Vérone, il n' est pas raisonnable de supposer que le Hillel glossateur soit un autre que lui; d' ailleurs, sans noter le mot șidduq, Steinschneider avait déjà relevé trois autres formes ou acceptions rares, communes à la traduction ou aux gloses du De causis et aux Tagmuley ha-nefeš ${ }^{21}$.

Récapitulation des arguments: pour l' attribution à Hillel de Vérone, 1) le fait que très peu d'auteurs et moins encore de traducteurs se nomment Hillel et sont médecins; 2) l'usage, commun aux Tagmuley ha-nefeš de Hillel de Vérone et aux gloses dont nous parlons, d'un texte rarement cité d' al-Fārābī; 3) surtout, des éléments caractéristiques de vocabulaire, en particulier le mot șidduq que seul Hillel de Vérone est connu pour employer; contre cette attribution, un argument unique, le fait que la traduction en question ne soit citée ni implicitement, ni explicitement, dans les tardives Rétributions (Tagmuley ha-nefeš), mais cela peut s'expliquer de diverses façons, y compris par une traduction encore plus tardive.

La question de l' attribution des notes peut cependant être posée à un autre niveau: étant admis que Hillel de Vérone soit le plus vraisemblable rédacteur des notes en hébreu qui accompagnent probablement sa propre traduction du Liber de causis, a-t-il fait preuve d'originalité dans ces notes ou a-t-il seulement traduit des éléments d'un commentaire latin? Steinschneider estimait qu'il s'agissait d'une traduction ${ }^{22}$. Notons seulement que nous verrons plus loin (5)

20 Le terme, rare, a quasiment la valeur d'une signature. Il se trouve quatre fois dans la traduction anonyme de la prop. 1 (une fois glosé en marge רטי[י[אונליטר], rationaliter), Yosef Sermoneta l'a relevé deux fois dans les Tagmuley ha-nefeš et il se trouve encore, dans le manuscrit d'Oxford (f. 82v), dans le texte Šelemuth ha-nefeš qui suit le De causis: Rothschild 1994, p. 411; Hillel de Vérone, Sefer Tagmulé ha-nefesh (éd. Sermoneta), p. 248; Steinschneider dans Hillel de Vérone, Sefer tagmuley ha-nefeš (éd. Halberstamm), p. 23 et f. כב et, 1.19 et 24 .

21 Dans Hillel de Vérone, Sefer tagmuley ha-nefeš (éd. Halberstamm), f. מב מבר, note: il s' agit de selah employé comme adverbe signifiant l'éternité (glose de la prop. 11[12]), de eyneymo, «ils ne sont pas» [avec suffixe archaïsant] (prop. 4) et de nolad pris au sens d'un «engendrement» de nature logique (longue note à la prop. 16(17), f. 79v, 8o).

22 Hillel de Vérone, Sefer tagmuley ha-nefeš (éd. Halberstamm), f. מא we-'ad ha-yom lo' eda'mi hu' ha-mefareš (ha-noșri) ašer debarayw ne'etequ mi-R. Hillel, «jusqu' aujourd' hui j' ignore quel est le commentateur (chrétien) dont les propos ont été traduits par Hillel»; noter que le même $\left(1893 ; 1956^{2}\right)$, p. 262 , ne parle plus de traduction strictement dite: «Ich glaube, Hillel hatte einen anonymen christlichen Commentar vor sich, und wahrscheinlich den des Thomas d'Aquino, aus dem er eine frappante Parallele giebt» (donc, deux 
que la recherche, à laquelle Steinschneider lui-même avait déjà dû procéder, de sources latines parmi les commentaires les plus répandus et à portée d'être connus, en Italie, de juifs extérieurs à l' université donne des résultats très partiels, pas assez pour parler d' une traduction, mais suffisamment pour supposer que le reste a pu être apporté par Hillel lui-même, qui de toute façon intervient lorsqu' il se réfère à Maïmonide ou à un Livre des principes qui n'est pas celui que les Latins connaissent.

Hillel b. Samuel b. Éliézer de Vérone était né en Italie entre 1220 et $123 \mathrm{O}^{23}$, peut-être à Forlìi ${ }^{24}$, où il passa ses dernières années et écrivit les Rétributions de l'âme ${ }^{25}$. Son grand-père, R. Éliézer b. Samuel, était un talmudiste renommé26. Il affirme avoir été étudiant, sans doute en médecine, dans les universités de Barcelone puis de Montpellier ${ }^{27}$. Dans la première de ces villes, il aurait été le disciple, entre 1259 et 1262, de Jonas de Gérone (R. Yonah Girondi). C'est peut-être celui-ci qui aurait fait naître chez Hillel une sorte de vénération pour Maïmonide. De retour en Italie, il exerça la médecine; il séjourna à Rome avant de se fixer à Capoue comme médecin ${ }^{28}$ tout en donnant des cours sur le Guide des égarés; le kabbaliste Abraham Abulafia y fut son élève. La fin de sa vie se passa à Forlì. On lui doit, selon Steinschneider ${ }^{29}$, d'avoir, le premier des philosophes juifs, utilisé systématiquement les sources latines ${ }^{30}$ et on pourrait voir en lui, toutes proportions gardées, une sorte d'Albert le Grand juif, dans la mesure où il est le premier à mettre en présence les sources de deux traditions qui s'ignoraient avant lui (la tradition latine et la tradition gréco-arabe en ce qui concerne Albert, la tradition grecque-arabe-hébraïque et la tradition

commentaires chrétiens; le parallèle avec Thomas, pour lequel il est renvoyé à Hebräische Bibliographie 6, 1863, p. 111, n. 2, est celui de la prop. 10(11)/12, note b; l'argument de Bardenhewer 1882 [v. infra, n. 46], que le recours à Thomas aurait empêché l'attribution qu' a donnée Hillel, est jugé faible: «Hillel konnte ein Exemplar ohne Prooemium vor sich haben, oder hatte einen Grund, Thomas' Ansicht nicht zu berichten»).

23 La plus récente mise au point est fournie par l'introduction de Schwartz, Fidora 2009, p. 948.

24 Vogelstein, Rieger, 1896, p. 26o, n. 2.

25 Hillel de Vérone, Sefer Tagmulé ha-Nefesh (éd. Sermoneta), p. Iv.

26 Vogelstein, Rieger, 1896, p. 400.

27 Vogelstein, Rieger, 1896, p. 272. Selon Sermoneta (1972; 2007), p. 113-115, nous n'avons aucune preuve de son séjour à Montpellier.

28 Dans une lettre qu'il lui adresse, un correspondant lui écrit: «ou il te suffit de visiter tes malades et d' examiner les urines», etc. (Oșar neḥmad 2, p. 142). R. Qalonymos b. Qalonymos, un contemporain, mentionne dans sa Masekhet Purim un «médecin Hillel».

29 Steinschneider 1874, p. 91.

$30 \quad$ Relevé des gloses latines des Tagmuley ha-nefeš, éd. Sermoneta, p. 250-253. 
latine, en l'occurrence, elle-même déjà enrichie par l'apport arabe, chez Hillel), sans parvenir à les rendre entièrement compatibles.

Son œuvre $^{31}$, bien moindre cependant que celle d'Albert le Grand, comprend des traductions médicales et des œuvres philosophiques personnelles. Il a traduit la Chirurgia magna de Bruno di Lungoburgo ${ }^{32}$; la Tégnè (Ars parva) de Galien ${ }^{33}$; une traduction des Aphorismes d'Hippocrate (Paris, BN, hébr. 1111) portant des notes marginales dont une au nom de «Hillel» peut-elle lui être attribuée sans autre preuve ${ }^{34}$ ? Ses œuvres personnelles sont un commentaire des vingt-cinq premières propositions du Guide des égarés 35 ; trois questions sur l'exercice par l'homme du libre arbitre, sur le châtiment d'Adam exercé aux dépens de l'humanité entière et sur les anges déchus ${ }^{36}$; un Ma’amar ha-darban (Livre de l'aiguillon) dont subsiste un fragment ${ }^{37}$; deux lettres au médecin Isaac b. Mardochée (Maestro Gaio) ${ }^{38}$; il correspondit aussi avec Zerahiyah Ḥen (autre traducteur du Liber de causis) et deux lettres conservées de celui-ci permettent de reconstituer la doctrine de son correspondant sur les points de l' origine du langage et sur la réalité historique des miracles bibliques (un position conservatrice dont se gausse Zerahiyah) ${ }^{39}$; peut-être écrivit-il un

31 Récapitulée récemment par Leicht 2013, p. 592-598, avec indication des manuscrits et des éditions.

32 Ms. Paris, BN, hébreu 972, f. 22v, titre: ha'ataqat Galianus we-Aleqsander. Sefer ha-keritut ha'ataqat R. Hillel be-Rabbeynu Šemu'el z"l kefi hagadat Ma'ešțro Bruno bi-lešon ha-noșri ha-ma'atiqo hu' me-hagadah (sic?) Galianus u-me-Abișino we-Almansor we-'Ali u-she'ar hakhamim qadmonim. - Il existe une dizaine d' autres témoins.

33 Avec le commentaire d' 'Ali b. Ridhwan, traduit du latin de Gérard de Crémone. Deux mss, semble-t-il: Paris, BN, hébreu 1111, f. 32-45v et Rome, Bibl. Casanatense 2834 (Sacerdote 201), f. 187-228v (édité par A. Berliner).

34 Comme se le demande Steinschneider dans Sefer tagmuley ha-nefeš (éd. Halberstamm), p. 9 .

35 Éd. Halberstamm, à la suite des Tagmuley ha-nefeš, f. 32v-40. Postérieur aux Tagmuley, qu'il cite.

36 Ms. Munich, Bayerische Staatsbibl., hebr. 120, f. 54-66v; v. éd. Sermoneta, p. Xv et n. 15; éd. par Steinschneider dans Sefer tagmuley ha-nefeš (éd. Halberstamm), f. 45-55. v. sur la première Sadik 2013, p. 292-314 (selon cet interprète, l'homme ayant été créé d'après R. Hillel pour choisir le bien, le choix du mal résulte d'un défaut «accidentel» d' exercice des facultés de l'âme et en particulier de l'intellect); sur la troisième, Sermoneta 1974.

37 Ms. BN, hébreu 704, f. 83v-86v; un ouvrage de ce titre est mentionné dans les Tagmuley; éd. I. Goldblum, Mi-ginezey Yiśra'el be-Fa'riz. S' agirait-il d' un autre ouvrage de même titre? Sermoneta n' en dit rien dans sa propre édition et ne se prononce pas sur l'attribution du texte de Paris.

38 Futur médecin du pape Nicolas IV (Sermoneta, 1972 ; 2007); Vogelstein, Rieger, 1896, passages notés dans l'index.

39 Sermoneta 1965, p. 11 et n. 18, renvoyant à l'éd. des lettres de Zerahiyah par R. Kirchheim dans Oșar neḥmad 2, 1857, p. 124-143 et à son propre travail Sermoneta 1962. 
ouvrage sur l' examen des urines (ms. Rome, Bibl. Casanatense 20o) et, avant tout, les Rétributions de l'âme (Tagmuley ha-nefeš), qui cherchent à concilier les notions rationalistes relatives à l'âme et les textes rabbiniques concernant sa rétribution, qu'il juxtapose en deux parties. Son redécouvreur au $\mathrm{Xx}^{\mathrm{e}}$ siècle, Giuseppe Sermoneta, discernait chez lui, en dépit de son rationalisme et de son dévouement à la pensée de Maïmonide, une authentique sensibilité aux dangers pour la foi que comportait la spéculation philosophique ${ }^{40}$; il estimait que, dans une crise qui selon lui (Sermoneta) faisait écho à celles de l'Université de Paris en 1270 et 1277, à l' occasion de la condamnation des thèses dites «averroïstes», la position de Hillel correspond à celle des aristotéliciens modérés de Paris, aussi éloignés des averrö̈stes radicaux que des anti-aristotéliciens «obscurantistes $»^{41}$.

L'enseignement dispensé à Abraham Abulafia pose la question d'une éventuelle étape kabbalistique dans son évolution. M. Yossef Schwartz, qui a introduit et traduit en allemand une partie des Tagmuley ha-nefeš, ne tranche pas mais note que les oppositions courantes entre philosophie d' une part, kabbale ou mystique d' autre part, ne valent pas dans son cas.

Confrontant les épistémologies juive, arabe et latine, Hillel, médecin, s'intéresse particulièrement dans les Rétributions à l' articulation de l' ontologie et de la psychologie: immatérielle, l'âme n'a plus, après la séparation d' avec le corps, moyen de s'individuer, et l'on rejoint la théorie averroïste de l'unicité de l'âme; Hillel l'évite par une solution de type néoplatonicien qui mêle des éléments avicenniens et gabiroliens: si l'intellect est la forme de l' âme, celleci acquiert le statut de principe matériel et devient principe d'individuation de l'intellect. En même temps, il refuse l'hylémorphisme aristotélicien au profit d' un cosmos néoplatonicien dans lequel les forces immatérielles peuvent se substituer à la causalité physique. Cette association du physique et de l'épistémologique est, selon M. Schwartz, caractéristique de la tradition tolédane de la réception d'Avicenne.

Le caractère «séparé» de l'âme, supposé rendre compte d'une capacité du mental à agir dans l'ordre physique ${ }^{42}$, s'entend en divers sens: à la fois

40 Sermoneta, 1972; 2007. Dans la première partie des Rétributions, R. Hillel traite le problème d' actualité de savoir si les âmes survivent individuellement ou si, comme le pensent les averroïstes, elles ne forment qu' une seule âme immortelle. Il se rallie à la première opinion, seule conciliable avec les données religieuses traditionnelles.

41 Sermoneta, éd. cit., p. IV-v.

42 C'est une doctrine qui reçoit à la même époque ses lettres de noblesse avec le commentaire du Canon d'Avicenne donné par le professeur de médecine Taddeo Alderotti à Bologne vers 1289, quoiqu' elle suscite l'opposition de certains de ses élèves, tel Gentile da Cingoli: Robert 2014, p. 152-167. 
l'incorporéité de l'âme et la différence ontologique de l'intellect qui l' informe, en tant que substance céleste, par quoi s'établit une continuité ontologique entre les entités célestes (appelées «corps» de manière homonymique) et l'intellect humain; en un troisième sens, thomiste, le composé humain d' intellect, âme et corps est unique en son genre, par là séparé à la fois des règnes angélique et animal. Hillel est plus proche de l'émanatisme d'Avicenne et de Maïmonide tel qu' il le comprend que de l' aristotélisme d'Averroès ou de Thomas. Encore l'émanation ne doit-elle pas être pensée comme un mouvement physique, l' absence de mouvement propre de l'âme expliquant à la fois, si nous comprenons bien les analyses de M. Schwartz, sa persistance dans un corps et son éternité. La capacité d'interférence des forces spirituelles dans le monde physique est probablement aussi en jeu dans les miracles et a permis à Hillel, d'une manière jugée paradoxale par M. Reimund Leicht qui en a traité récemment ${ }^{43}$, de défendre l' autorité de Maïmonide, maître à penser des rationalistes, en recourant à des récits miraculeux. Tel est le fond sur lequel vient s' inscrire l'intérêt, lui-même ambivalent, de Hillel, à la fois traducteur et critique du Livre des causes.

Un autre point de l'introduction de M. Schwartz aux Rétributions de l'âme est à rappeler ici: chez Hillel, un triple substrat, fait de textes hébreux originaux, de traductions hébraïques à partir de l'arabe, antérieures à Hillel, et de ses paraphrases personnelles de textes latins, a pour conséquences une syntaxe parfois obscure, une logique différente d' une source à l' autre et un vocabulaire novateur, non-tibbonide, changeant lui aussi selon les sources, par là également difficile en l' absence d' autres textes formant avec celui-ci une Diskursgemeinschaft qui aiderait à restituer à sa langue un sens suffisamment univoque.

4) La datation: Hillel de Vérone aurait écrit à Forlì, à la fin de sa vie, après $1287^{44}$, les Rétributions, selon Steinschneider en 1291. Steinschneider, sur la base d'une citation du De causis dans les Tagmuley ha-nefeš dans laquelle le mot-clef de «cause » n' est pas traduit de la même manière que dans sa traduction du De causis, estime celle-ci postérieure, jugeant invraisemblable que Hillel se soit écarté de son propre choix, s'il avait été antérieur ${ }^{45}$. En revanche, Bardenhewer croit que la citation de la prop. 5 rapportée à un ouvrage sur les substances supérieures en trente-deux chapitres sous le nom de Platon, dans les Imrei šefer («Paroles de beauté») d'Abraham Abulafia, ouvrage de 1291, ne peut avoir pour

\footnotetext{
43 Leicht 2013.

44 Voir supra, n. 25.

45 Steinschneider 1852-186o, col. 742 (eodem fere tempore [que la traduction de Zerahiyah Hen (1284) ]); id., dans Halberstamm, éd. cit., p. 10; puis id. 1893; 1956 $6^{2}$, p. 267.
} 
source que Hillel (cette désignation et cette attribution lui font évidemment écho), ce qui suppose sa traduction antérieure ou remontant au plus tard à $1291^{46}$; d'un autre côté, il la pense peu postérieure à celle de Zerahyah Ḥen $(1284)^{47}$. Une datation approximative de la traduction du Liber de causis circule depuis les années 1980, apparemment sans fondement; elle place l'ouvrage entre 1250 et $129 \mathrm{o}^{48}$, soit indifféremment de part et d' autre d'un moment pourtant décisif de la réception latine du De causis, l'identification par Thomas de sa source principale.

La proposition initiale d'attribution des théorèmes à Platon et la note critique de la proposition 16(17) permettent pourtant de préciser quelque peu:

a) en l'absence de source connue comportant cette attribution à Platon, on est tenté d'y voir une transposition de l'attribution à Proclus, qui ne se rencontre qu' après la découverte par Thomas d'Aquin de la relation étroite entre le Liber de causis et l'Elementatio theologica, exposée dans son commentaire en 1272, à la suite de la traduction de l'Elementatio par Guillaume de Moerbeke en $1268^{49}$. Le traducteur hébreu continue cependant d'attribuer les développements à al-Fārābī, ce qui pourrait relever du régime, antérieur, des premiers commentateurs latins qui attribuaient les théorèmes à Aristote et les développements à al-Fārāb $\bar{~}^{50}$. Toutefois, Gilles de Rome lui aussi, bien qu' au courant de la découverte faite par

46 Bardenhewer 1882, p. 318-320. C'est qu'Abulafia fasse état de trente-deux propositions qui fait supposer à Bardenhewer que sa source est Hillel plutôt que la traduction antérieure (1284) de Zerahiyah b. Še'alti’el Ḥen, qu' il connaît (p. 305-308); il pense en effet que l' attribution à Platon n'était pas rare, pourrait donc avoir eu une autre source.

47 Bardenhewer 1882, p. 308, n. 1: «Nicht viel später anzusetzen als die Übersetzung Serachja's».

48 Rothschild 1994, p. 405: «XIII [ [3/4] s.»;Zonta 1996, p. 228: «probabilmente verso il 1290», sans doute à la suite de Sermoneta 1965, p. 34, n. 70: «nel 129o o nel 1291, forse a Forlì»); Über die Vollendung der Seele, p. 11, «gegen Ende seines Lebens in Forlì [...] während der

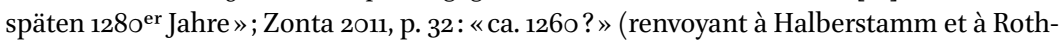
schild, déjà cités), suivi par Rothschild 2013a, p. 394: «vers 1260». Aucune de ces datations n' est motivée.

49 Thomas d' Aquin, Super Librum de causis expositio, p. XXXIV-XXXv pour les deux dates.

$5^{\circ}$ Cf. D'Ancona 1992a, p. 215-216: dans la «première réception latine du De causis», les lemmes sont attribués à Aristote et les explications à d'autres auteurs; huit manuscrits parmi les quatre-vingt-douze examinés par Pattin ainsi que les commentaires du Ps.-Henri de Gand et du Ps.-Adam de Bocfeld attribuent ces explications à al-Fārābī; Albert y voit l'un des auteurs mis à contribution, avec Aristote, Avicenne et Algazel, par l' auteur. - La double attribution initiale «s' explique comme une réaction à l' apparition d'un ouvrage qui devait appartenir à Aristote, mais qui, en même temps, était tellement différent des autres ouvrages aristotéliciens connus» (ibid., p. 217). Bardenhewer 1882, p. 56, proposait que cette attribution eût sa source dans une confusion avec le Liber de principiis d'al- 
Thomas, maintient l'attribution, peut-être, des développements, assurément au moins de leur choix et de leur arrangement, à al-Fārābīist .

b) La critique de la prop. 16(17) comporte une référence au «l. XI de la Métaphysique» dont il serait raisonnable de penser, en contexte fortement théologique, qu'il s' agit du Livre $\Lambda$; ce qui théoriquement placerait ce texte avant la numérotation en quatorze livres, inconnue auparavant des Latins (et de la tradition arabe à laquelle Hillel aurait pu avoir quelque autre accès) opérée par Guillaume de Moerbeke dans sa traduction dont la première rédaction serait datable fin 126o-1261 et la seconde entre 1266 et 1268 , au plus tard $1270^{52}$; et qui, pratiquement, ne nous apprendrait rien, la rapidité avec laquelle une découverte textuelle de cette nature aurait pu arriver à la connaissance d'un juif étant tout à fait inconnue. Toutefois, la référence paraît plutôt être au Livre K, ce qui fournit un terminus post quem effectif.

c) L'élément le plus sûr tient dans la référence au De ente et essentia de Thomas d'Aquin, à propos de la prop. 31(32), puisque cet ouvrage a été écrit entre $125^{2}$ et $1256^{53}$.

d) Ensuite, on pourrait, à la suite de Steinschneider, tirer argument de l' absence déjà mentionnée de référence à la traduction du De causis dans les Rétributions de l'âme pour proposer que Hillel ne l' eût connu et à plus forte raison traduit qu' après avoir écrit ce traité. Mais cet argument a la fragilité des preuves $a$ silentio ${ }^{54}$.

e) Enfin, nous croyons percevoir quelques affinités avec le commentaire de Thomas d'Aquin (1272), et même quelques signes de proximité avec le commentaire de Gilles de Rome (v. 129o). Nous croyons, quoi qu' il en soit, pouvoir nous fier au critère de l' attribution au courant platonicien pour proposer comme la plus vraisemblable une date en tout cas postérieure à 1272.

Fārābī, texte que Hillel, précisément, rapproche du De causis; cependant, ce De principiis ne semble pas connu en latin.

51 Gilles de Rome, Expositio super auctorem De causis, n.p., division M: Causa vero efficiens ignoratur, sed creditur a multis fuisse Alpharabium [...] in greco autem habentur propositiones Procli, a quibus hae propositiones emanauerunt.

52 Aristote, Metaphysica, transl. G. de Moerbeka, p. 249-268 (en part. 249, 253).

53 Thomas d'Aquin, De ente et essentia, éd. Leonina, p. 319-320.

54 Steinschneider estime (éd. Halberstamm, p. 10) qu' il y a dans Tagmuley ha-nefeš des citations du Liber de causis, selon une autre traduction; mais les éditeurs postérieurs (Sermoneta, Schwartz) ne les y ont pas trouvées; de plus, rien n' empêcherait que Hillel n' ait plus disposé de son texte et ait dû citer d'après une autre traduction, ou de mémoire, ou ait retraduit. 
5) Affinités, donc, avec les commentateurs latins: elles semblent assez minces. On relève quelques traces littérales qui font penser à un accès au moins partiel au commentaire de Thomas: dans la note à la prop. 1, que si la cause première agissait directement dans le causé, la cause seconde serait inutile, s'appuie peut-être sur Thomas citant Proclus, Elementatio theologica, 56 : «Omne quod a secundis producitur, et a prioribus et causalioribus producitur eminentius, a quibus et secunda producebantur» (Saffrey, p. 5, l. 18-20), ce qui donnerait à penser que la cause seconde soit seulement plus faible que la cause première; toutefois, l' objection suppose d'ignorer la suite du commentaire de Thomas aussi bien que l' exemple cité par le développement de la proposition (Pattin, $\S \S 6-11)$, figurant pourtant peu après le lieu de cette intervention dans le texte hébreu. De plus, il n' est pas impossible de retrouver le germe d' une autre question chez Thomas (Saffrey, p. 9, l. 10-11).

La critique de la prop. 10(11) présente des points communs de forme $\mathrm{e}^{55}$ et de fond avec le commentaire de Thomas, lequel d' ailleurs lui restitue son intelligibilité (v. infra la traduction commentée des notes).

Dans la note à la prop. 11(12), en insistant en termes d'influx sur la particularité de chaque mode de présence d'une substance en l'autre, et en écartant l'hypothèse d'un influx, Hillel pourrait faire écho à la fin du commentaire de Thomas (Saffrey p. 81, l. 10-12, mais en termes de similitudines et species).

En 16(17), Hillel parait emprunter deux éléments au commentaire des propositions voisines par Thomas: 15(16) (Saffrey, p. 93, l. 20-21) sur ce que le texte doit être corrompu, et 17(18) (Saffrey, p. 102, l. 7-8) pour l' exemple du feu et de la chaleur.

En 29(30), on trouve trace d'une distinction de Thomas (Saffrey, p. 134, l. 810), citant Proclus, entre secundum suam substantiam et le per substantiam du De causis; Hillel opère comme Thomas le rapprochement avec la proposition précédente (ibid., l. 1: Hic ponitur propositio conversa [cf. mithafekhoth] prioris). Toutefois, alors que Thomas oppose des substances dépendantes du temps et d' autres, subsistantes par soi, Hillel s' en tient à l'opposition plus générale entre substances par soi et substances dépendantes d' autre chose.

En 30(31), on est proche de Thomas (Saffrey, p. 141, l. 10-p. 142, l. 3) qui envisage successivement cette position intermédiaire entre le temps et l'éternité pour le corpus caeleste et pour l'âme; toutefois, Thomas conclut à propos du premier qu'il ne relève que du temps; et, quant à la seconde, il ne formule pas comme Hillel de restriction à «certains degrés». cepta, multa fundamenta catholicae fidei tollerentur. 
En 31(32), le lien établi avec la proposition précédente est analogue à celui qu' opère Thomas (Saffrey, p. 143, l. 1-p. 144, l. 3), par l' intermédiaire de la prop. 107 de Proclus, quoique la présence du temps dans l'éternité et de l'éternité dans le temps soit peut-être mal comprise. Le long développement sur le Premier participé et non participant est parallèle à celui de Thomas (Saffrey, p. 144, l. 28-p. 145, l. 14). Ajoutons pour mémoire que cette dernière intervention se termine par la traduction d'un bref extrait du De ente et essentia de Thomas.

Quelque connaissance du commentaire de Gilles de Rome paraît cependant aussi ${ }^{56}$ : d'abord, l'attribution à Platon et à al-Fārābī, figurant au prologue. Ensuite, les objections posées contre la prop. 1 sont explicitement formulées chez Gilles ${ }^{57}$; l'étonnant, cependant, est qu'il n' en paraît que la formulation, sans les solutions qu' il apporte lui-même; aussi pourrait-on supposer qu' elles se sont présentées spontanément à l' esprit de Hillel, ou qu'il a suivi quelque autre source (ou entendu quelque dispute) qui posait les mêmes questions ${ }^{58}$ mais n'apportait pas de solutions, ou encore que ces dernières ne lui ont pas convenu.

En 10(11)b: «Cependant le commentaire de cette proposition est contraire à la foi et il n'y a pas à s' appuyer sur lui». Ce jugement porte logiquement sur la partie omise du développement, dont n'a été expressément rapportée que la

56 Steinschneider 1863, p. 212, en doutait: «Die Übersetzung des Jehuda hat sowenig als die des Hillel etwas mit Aegidius zu thun» (il est vrai qu'il parle plutôt de la traduction ellemême); dans Steinschneider 1893, p. 262-263, il fait état d'un commentateur chrétien anonyme et de Thomas, sans nommer Gilles.

57 Gilles de Rome, Expositio super auctorem De causis, f. 2vM: Dubitaret forte aliquis, quia videtur falsum [...] quod causa prima prius attingat causatum quam causa secunda, et quod ultimo recedat ab eo [...]. Non ergo plus influit causa prima, nec eius influentia ultimo recedit, sed videnter haec omnia simul esse; f. 4rY: quomodo causa prima adiuuet operationem causae secundae, et det ei quod agat; f. 4vAA utrum omne illud quod efficit causa secunda efficiat causa prima; f. $5 \mathrm{rEE}$ : Cum ergo quaeritur utrum aliquo modo producatur effectus a causa secunda, quo (scil.: quod) non producatur a causa prima, vel econverso; f. $5 \mathrm{vGG:} \mathrm{quo-}$ modo causa prima vehementius et fortius agit in re, et quomodo est maioris adhaerentiae cum re quam causa secunda; ibid. II: quomodo causa prima conseruat causam secundam in actione sua; f. $6 \mathrm{r}$ : si res procedit a causa prima sub esse magis universali a causa vero secunda sub esse magis speciali [...] causa secunda magis faciet ad esse rei quam causa prima.

$5^{8}$ L' arsenal n' en est pas illimité et nous trouvons aussi dans le Ps.-Henri de Gand, Quaestiones in Librum de causis, q. 5 (p. 27-28), peut-être, le même problème que dans la q. 1a/ii dus ms. hébreu; aux q. 9-13 (p. 33-39), assurément, ceux des qq. 1a/iii et 1b de l'hébreu). Il nous a paru cependant moins vraisemblable que Hillel ou son annotateur ait eu connaissance d'un auteur sans rapport avec l'Italie. 
fin («Le commentateur dit à la fin de l' explication, avec force»). Cette dernière glose reprend sans doute à peu de chose près la formulation de Thomas, mais renvoie par là non, comme lui, à la fin du théorème (Saffrey, éd. cit., p. 73, l. 4-5: «signanter autem dicit quae non destruuntur neque cadunt sub tempore», où il s' agit de la fin de la proposition proprement dite ${ }^{59}$ ), mais à la démonstration, dont il supprime le début à cause de l'incompatibilité doctrinale. On pourrait supposer dès lors un recours parallèle à Gilles, qui conteste le même point que Thomas, mais à propos du début du «commentaire» (f. 39v).

Puis, en 11(12), Hillel, dont nous avons dit qu' il pourrait faire écho à la fin du commentaire de Thomas (Saffrey p. 81, 1.10-12, en termes de similitudines et species), est plus proche de Gilles (f. 41v), qui marque plus nettement la hiérarchie descendante que suppose l' «épanchement d'épanchement» dont parle Hillel et qui emploie fluunt, comme Hillel le terme d' «épanchement».

À la différence de la légère présence de Thomas, qui se manifestait par quelques similitudes littérales, celle de Gilles est à la fois rare et plus abstraite: on pourrait imaginer que Hillel, plutôt que de lire le commentaire même de Gilles, ait pu en percevoir quelque écho dans un échange informel avec des savants chrétiens ou en assistant à quelque controverse publique. Une telle hypothèse présente l'inconvénient de dispenser à peu de frais de rechercher des sources précises mais c'est peut-être à elle que conduisent des tentatives infructueuses du passé pour identifier des références chrétiennes, chez Gersonide par exemple ${ }^{60}$, aussi bien que la vraisemblance des réalités sociales.

6) La doctrine des notes: sous réserve de ce que le traducteur anonyme et l'intervenant Hillel (b. Samuel) soient bien tous deux Hillel de Vérone (ce qui est apparu plus haut comme très probable), nous disposons du cas privilégié d'un traducteur qui réagit lui-même au texte qu'il traduit, à ses contradictions internes, obscurités ou redondances et, ce qui nous intéresse davantage, aux contradictions dans lesquelles ce texte nouveau peut entrer par rapport aux doctrines tenues, ou au moins déjà connues, par lui, traducteur. Si le commentateur n'était pas le célèbre Hillel de Vérone et n'était pas le même que le traducteur (ce qui, nous l'avons vu, est le moins probable), nous aurions tout de même affaire à la seule critique interne et externe portée, à notre

59 Ce n' est pas, cependant, que signanter veuille dire «comme à titre de signature», ce mot, qui figure à diverses reprises dans le commentaire de Thomas, signifiant en latin médiéval «de manière signalée, expressément».

6o Voir Pinès 1967; Möbuß 1991; Sirat, Klein-Braslavy, Weijers 2003. 
connaissance, par un lecteur juif, sous la forme d'un commentaire suivi, sur l'ensemble du Liber de causis ${ }^{61}$.

Si le métalangage de Hillel est rigoureux, il faut distinguer chez lui deux types d'interventions: le type introduit par le mot peyruš («explication») qui est anonyme et au service du texte (voire, résume le développement originel de la proposition lorsqu' il est omis, comme il arrive fréquemment dans la troisième dizaine de propositions), et les interventions introduites par Amar Hillel, qui introduisent des objections ou remarques de son propre chef. Avant de présenter la partie critique des notes, il convient de dire un mot de la brève introduction que le traducteur donne au texte: Tout en proposant la double attribution des théorèmes à Aristote (et plus probablement à Platon) et celle des commentaires à al-Fārābī, ce qui est courant, Hillel est à notre connaissance le seul à faire état d'un rapport privilégié avec ce qu'il nomme le Livre des principes de ce dernier, plus connu comme traité de philosophie politique, le Livre du gouvernement ${ }^{62}$, mais qui existe en hébreu sous ce titre de Livre des principes $^{63}$ et qui semble inconnu en latin ${ }^{64}$. En vérité, la première moitié

61 La traduction d'une partie du commentaire de saint Thomas par Juda Romano, l'usage tacite et partiel qu'il peut avoir fait du Liber de causis dans ses ouvrages personnels, celui, explicite mais tout aussi partiel, qu' en a fait Moïse b. Sabbataï en annotant sporadiquement la traduction de Juda Romano et en employant certaines propositions du De causis à l' appui dans sa polémique contre les kabbalistes (v. supra, n. 4), n' ont pas la même importance à cet égard.

62 Al-Fārābī, Kitāb as-suyāsa al-madaniyya, éd. Najjar; éd. et trad. espagnole R. Ramón Guerrero 1992, p. 1-70, analysé par Munk 1859, p. 344-347 (p. 344-345: «les six principes des choses sont: $1^{\circ}$ le principe divin, ou la cause première, qui est unique; $2^{\circ}$ les causes secondaires ou les Intelligences des sphères célestes; $3^{\circ} \mathrm{l}^{\prime}$ intellect actif; $4^{\circ} \mathrm{l}^{\prime}$ âme; $5^{\circ}$ la forme; $6^{\circ}$ la matière abstraite (hylè). Le premier de ces principes est l'unité absolue, tandis que tous les autres représentent le multiple. Les trois premiers ne sont ni des corps, ni en rapport direct avec les corps; les trois derniers ne sont pas en eux-mêmes des corps, mais sont unis aux corps. Les genres des corps sont au nombre de six, savoir: les corps des sphères célestes, l' animal raisonnable, l' animal irraisonnable, les végétaux, les minéraux et les quatre éléments. L'ensemble composé de ces six genres forme l'univers. - Après qu'il a parlé de tout ce qui dérive des six principes et qu'il est arrivé à l'homme, il examine l'organisation de la société», etc.).

63 Al-Fārābī, Sefer ha-asif, 1849 (réimpr. en Israël, [5]730-[1969/70]), p. 1-64. Voir Steinschneider, Steinschneider 1893, p. 290-292, signalant l'attribution probablement erronée de la traduction hébraïque dans le manuscrit qu'il a utilisé à Samuel Ibn Tibbon plutôt qu'à son fils Moïse, faisant état de plusieurs autres manuscrits et notant l'obscurité du style ainsi que le manque de correction de l'édition.

64 Il paraît sans rapport avec le Liber sex principiorum mis à partir d'Albert le Grand sous le nom de Gilbert de la Porrée ((Ps.-)Gilbert de la Porrée, Liber sex principiorum; éd. d'un texte récrit par Hermolaus Barbarus dans la $P L$ 188, col. 1257-1270) mais donné comme anonyme par Roger Bacon (Minio-Paluello, p. XLVII) et Thomas d'Aquin (Minio-Paluello, 
y est consacrée successivement aux principes métaphysiques (éd. Filipowski, p. 1-17), puis à une description de l'agencement des «choses secondes» qu' on peut regarder comme une cosmologie (p. 18-31), avant que ne soient introduits l'homme et la société. Hillel s'y référera deux fois dans ses notes sur le texte.

La critique doctrinale, telle qu' elle ressort des interventions sous le nom de Hillel inscrites dans la justification du texte, peut se répartir en trois blocs: pour procéder du plus simple au plus complexe, les interrogations d' un médecin, probablement; une défense théologique de l'unité et de la transcendance divines; diverses questions métaphysiques dans lesquelles la doctrine du Liber de causis paraît en contradiction avec des autorités, voire, si l' on voulait attribuer aussi à Hillel les notes anonymes et marginales à la prop. 1, radicalement discutable dès son début.

Deux questions touchent l'épistémologie médicale: la première n'est pas sous le nom de Hillel: en $\mathrm{b}$ il est observé que les processus physiologiques ne vérifient pas la célèbre thèse initiale, que la cause première agit dans le causé en l'absence de la cause seconde: à défaut du sang et des humeurs, les causes plus lointaines, les éléments et les végétaux sous forme alimentaire, n' agiraient pas sur le corps. Le second point touchant à la médecine est bien sous le nom de Hillel, en 1o(11)a: si, comme l'énonce le Liber de causis, il n'est de science que de ce qui n'est pas soumis à la corruption, quel est le statut de la médecine? Ici, le lecteur critique paraît consentir à cette thèse, puisqu'il commente en disant que c' est ce qui a obligé Avicenne à relativiser le statut scientifique de la discipline en question en la définissant comme une science pratique; il ajoute cependant qu' il y aurait «d' autres réponses», mais sans en dire plus. On peut ajouter à ces marques avérées d'un intérêt médical le choix d' un exemple suffisamment usuel en physique et en métaphysique pour ne pas faire preuve à lui seul: dans la critique de la proposition 16(17), l' illustration de divers niveaux de causalité (au moins deux, essentielle et accidentelle) par l' exemple d'un corps

p. XLVIII); ce livre est pourtant cité occasionnellement dans les commentaires au $D e$ causis, à propos de la forme qui est le premier principe dont il traite (ainsi par le Ps.Henri de Gand, Quaestiones in Librum de causis, p. 105, et par le Ps.-Adam de Bocfeld, cf. D’Ancona 1992a, p. 207, n. 70). Davantage, le commentant, Antoine André (ca 12801320) note qu' «Alii dicunt quod fuit Alpharabius commentator libri De Causis», d' autres, que c' est Gilbert (Minio-Paluello, p.XLVIII): la communauté de titre est-elle le simple effet d'un caractère commun de «principes» (ceux du Liber sex étant forme, action, passion, temps, lieu, position, habitus, plus ou moins, avec d'inévitables recoupements) ou bien existe-t-il une affinité quelconque entre les deux ouvrages? Hillel aurait-il été aiguillé vers ce texte à la lecture d'un commentaire latin qui se référait au Ps.-Gilbert de la Porrée, de manière plutôt circulaire si, comme l' indiquait Bardenhewer, l' attribution du De causis à al-Fārābī venait elle-même de son De principiis? 
humain échauffé, du feu (cause essentielle) et des modalités accidentelles du rapprochement des deux (proximité d' un feu, mouvement, nourriture et boisson chauds, air chaud).

Sur le plan théologique, des défenses des doctrines de la création et de l'unité et de la transcendance divines s'expriment à trois reprises. Le second commentaire (b) de la prop. 10(11) (à vrai dire, une seule phrase de celui-ci, qui n'en compte que deux dans l'édition Pattin) est purement et simplement déclaré omis comme «contraire à la foi», tel qu' on «ne doit pas prendre appui sur lui ». Il serait malaisé de dire ce qui a indisposé Hillel s'il n' apparaissait pas qu' il utilise ici le commentaire de Thomas d'Aquin, dont la critique est explicite. Le passage omis est le $\S 101$ de l'édition Pattin:

Quod est quoniam si intelligentia est semper quae non movetur, tunc ipsa est causa rebus sempiternis quae non destruuntur [nec permutantur] neque cadunt sub generatione et corruptione. Et intelligentia quidem non est ita, nisi quia intelligit rem per esse suum, et esse suum est sempiternum quod non corrumpitur $\langle\ldots\rangle$.

Telle est la critique de Thomas: si un intellect immuable ne crée que des choses éternelles, alors ni les anges ni Dieu ne peuvent intervenir dans le cours des choses et, davantage, le monde lui-même sera éternel.

On croit aussi trouver, dans les mises en garde de Hillel, l' écho de la critique par Maïmonide des attributs divins (Guide des égarés, I, 51-60) ${ }^{65}$. La discussion de la prop. 16(17) est longue et assez peu claire dans le détail. Elle comporte, comme on l'a déjà indiqué, une distinction entre cause essentielle et cause d'un degré inférieur (celle-ci, qui prend l'exemple du feu, pourrait développer une brève notation de Thomas d'Aquin à la prop. 17(18), p. 102, l. 4-8: «in unoquoque genere est causa illud quod est primum in genere illo [...] ignis est primum calidum a quo omnia caliditatem sortiuntur»). Cette distinction vise à relativiser le sens dans lequel la proposition semble énoncer que l'unité soit la cause de l'infinité. Hillel élargit la discussion à deux autres propriétés qui

65 Cf. Moïse Maïmonide, Le guide des égarés, I, 53, t. I, p. 205-216 (ch. 51-6o, p. 182-266), sur ce que les attributs ne sont pas séparés en Dieu mais ne font que décrire pour les hommes les actions diverses procédant d' une vertu unique. Il en résulte évidemment l' absence de dépendance de l'un par rapport aux autres. C'est peut-être de ce même refus de distinguer en Dieu des attributs essentiels que Hillel tire l' objection rapportée ensuite au nom de Maïmonide contre la métaphore du feu et du chaud qui, comme il le dit, ne regarde pas la présente question d'une éventuelle hiérarchie des attributs. 
accompagnent celles-ci, le fait d'être premier et le fait d'être une forme séparée; il insiste beaucoup, en terminant, sur ce que ces propriétés sont toujours simultanément présentes (c' est peut-être en ce sens seulement, selon lui, que l'on peut dire que l'une est «cause» des autres). S'il est vrai qu' il s' agit, tant dans la proposition et dans son développement que dans la note de Hillel, de tous les existants supérieurs, on est tenté d'assigner à cette note, la plus longue de toutes, l' enjeu de ne pas réduire Dieu, de même, à un de ses attributs, et de ne pas le subordonner à celui de l' unité. Hillel se réclame ici du Livre des Principes d' al-Fārābīín, cite également la Métaphysique, XI (apparemment, non le Livre $\Lambda$, mais le Livre $K$, sur la non-divisibilité de l'infini en acte), peut-être aussi le lib. II à à propos du caractère premier de l' un, si notre correction du texte hébreu est justifiée.

À l'occasion de la proposition $17(18)$, Hillel met en garde contre le risque d'attribuer à Dieu la vie, comme s'il en participait à la manière des existants créés. Elle ne s' applique à lui que de façon figurée (ou faut-il dire: équivoque?), pour deux raisons: loin d'en être pourvu, il en est le principe même, ce que marque en hébreu l'adjectif (au singulier) qui lui est pour ainsi dire réservé (hay), alors que le nom de la vie (à laquelle participent les existants créés), hayyim, est morphologiquement un pluriel; seconde raison, la définition de la vie suppose un corps animé, ce qui ne sied évidemment pas à Dieu. La notion d'usage figuré des mots vient sans doute encore de la critique des attributs divins par Maïmonide, quoique, peut-être, l' annotateur se souvienne ici à nouveau du commentaire de Thomas d'Aquin, p. 102, 1. 4-24 sur la différence entre une qualité telle qu' elle se trouve dans son principe et telle qu' elle se rencontre par participation dans des existants d'un degré inférieur.

Cette insistance répétée sur la transcendance absolue serait bien dans l' esprit de l' attachement farouche à une doctrine maïmonidienne sans concessions de l'unité divine que Sermoneta attribuait à Hillel de Vérone.

Quelques autres résistances doctrinales peuvent se ramener à des questions de vocabulaire ou, en d'autres termes, d'harmonisation de sources. Ainsi, la note sur la proposition $14(15)$ reconnaît la thèse célèbre de la coïncidence de l'intellect, de l'intelligent et de l' intelligible à propos de laquelle Hillel renvoie sans plus aux Six Principes d' al-Fārābī et à Maïmonide (Guide, I, 68).

La note sur la proposition $3 \mathrm{O}$ (31) se borne à traduire l' ontologie abstraite du De causis dans les termes de la plus familière cosmologie aristotélicienne.

66 Éd. cit., p. 1, mais qui formule l'implication inverse: «ce qui est premier ne peut être pluriel, mais seulement un et simple» (משה שבמדריגה הראשונה אי אפשר שיהיה הרבה אלא (אלחי (אחד פשוט לבד 
Singulière apparaît la note à la prop. 11(12) [24 dans le ms.] qui, sans objection ni référence à quelque autre manière de formuler les choses, se borne à éclairer un point de doctrine à vrai dire très spécifique, peut-être en s' aidant de Gilles de Rome.

Plus difficiles, et sans doute en correspondance souterraine l'une avec l'autre, les interventions des propositions 28(29) et 31(32).

À la proposition $28(29)$, il semble que pour Hillel, une essence puisse être soit auto-suffisante, soit engendrée par autre chose, contrairement à ce que lui paraît vouloir dire ici le De causis, que toute essence serait inengendrée. Il parait, d' après quelques éléments formels, avoir sous les yeux le commentaire de Thomas d' Aquin, quoiqu'il soit très éloigné de le suivre dans le détail.

À la proposition 31(32), il prend expressément dans le De ente et essentia de Thomas d'Aquin, dont il traduit une phrase, une distinction entre existence absolue et participée. Dans les deux cas, il s' agit d' introduire une précision qui manque sinon aux notions mises en œuvre dans le Liber de causis, du moins à son vocabulaire.

Enfin, c' est la célèbre thèse initiale de la proposition 1 (avec sa reformulation à la proposition 11(12)/24) qui est l'objet d'une pluralité de critiques (rappelons que les notes à la prop. 1 sont anonymes et que leur attribution à Hillel n' est pas sûre): l'intervention la en comporte trois:

i) si la cause première agissait directement dans le causé, la cause seconde serait inutile (peut-être d' après Thomas citant Proclus, Elementatio theologica, 56 , qui énonce que ce qui est produit par les causes secondes l'est de façon plus éminente par les causes premières, mais à condition d'ignorer la suite et l' exemple de l' existant, de l' animal et de l'homme).

ii) On ne voit pas, dans cette succession de causes, la place de la disposition virtuelle que comporte la chose (est-ce la «puissance passive» de Métaphysique IX, 1, 1046a 10 sqq. et 6, 1048a 30 sqq.?).

iii) La cause première, générale, ne rend pas compte des particularités individuelles (question formulée au moins chez Siger de Brabant et chez Gilles de Rome, problème abordé, quoique sans la forme de question, par Thomas); l'intervention $\mathrm{lb}$ ajoute un autre motif (que nous avons déjà mentionné à propos du point de vue médical porté sur le texte), à savoir:

iv) la cause seconde est indispensable à la transmission de l'action de la cause première.

Les arguments (i) et (iii) pourraient procéder d' une mécompréhension du texte critiqué (celui-ci n'a jamais dit que la cause première suffisait à faire exister la chose); à moins qu' au contraire ils ne feignent d'accepter ses présupposés implicites pour en montrer l'impossibilité: la cause seconde ne saurait pouvoir ce que la cause première ne peut pas, car elle serait alors plus puissante 
qu' elle: donc la cause seconde ne sert à rien; donc, aussi, existant seule la cause première, générale, les particularités individuelles ne s' expliquent pas: double conséquence absurde; l' argument (ii) possède une source philosophique respectable dans la Métaphysique; l'argument iv où se pose, nous l' avons vu, la difficulté d' articuler discours métaphysique et discours naturaliste, lui non plus n' est pas sans valeur.

Il est cependant possible de retrouver ces questions sinon, de manière explicite, chez Thomas d'Aquin lui-même, du moins chez Gilles de Rome, et au moins deux d' entre elles, bien plus tôt, chez le Ps.-Henri de Gand; cependant, le parallèle n' est que d'argument, sans que nous ayons identifié un exemple ou une forme de raisonnement communs; or les objections élevées par l'un et l'autre paraissent de celles que tout étudiant en philosophie est en mesure de formuler spontanément au vu de ce théorème.

Traducteur critique, Hillel de Vérone (si c' est bien lui) témoigne ici, comme dans son ouvrage personnel des Rétributions de l'âme, d' une volonté de synthétiser une source néoplatonicienne reconnue comme telle (ou plutôt deux: le Liber de causis et le Traité du gouvernement ou Traité des principes d'al-Fārābī) avec la métaphysique d'Aristote et avec la théologie de Maïmonide exposée dans le Guide des égarés; ou, mieux, il les confronte sans dissimuler la difficulté de les accorder. Son originalité en tant que commentateur du De causis tient sans doute aux critiques qu'il lui adresse: son désaccord avec la célèbre première proposition apparaît radicale (si les notes marginales sont de lui); aux propositions 16(17) et 17(18) en revanche, il s' agit surtout de mettre en garde contre des suites possibles du réaménagement du schéma de Proclus dans un système qui place Dieu au sommet, qui aboutiraient à un discours impropre tenu par rapport aux attributs divins. Enfin, tel le peintre qui se représente parmi les personnages de son tableau, le médecin traducteur a fait part des questions spécifiques que le Liber de causis posait à sa discipline. Ce traducteurcritique, encore une fois, tient dans l'histoire du Liber de causis une position singulière. Pour revenir à notre point de départ, il est loin de clarifier de manière irrésistible les motifs pour lesquels toute une famille de pensée du judaïsme italien a manifesté pour ce livre un intérêt exceptionnel. 
Annexe: Texte, traduction française et commentaire des notes ${ }^{67}$

Titre-préface:

זה הספר נקרא מאמר הל"ב הקדמות וקצת יחסוהו אל אריסטו, אבל הרוב אומרים

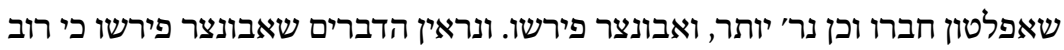

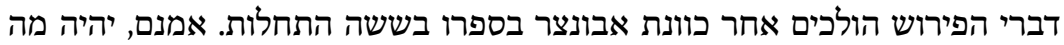

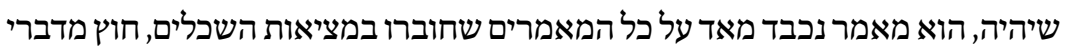

אריסטו.

Ce livre s'intitule Écrit des trente-deux propositions. Certains l' ont rattaché à Aristote mais la plupart disent que Platon l'a rédigé, et c'est ce qu'il semble davantage, et qu'al-Fārābī l'a commenté, et cela paraît vraisemblable car la plus grande partie du commentaire est conforme à l' orientation d' al-Fārābī dans son livre des Six Principes. Quoi qu' il en soit, c' est un écrit très important, [au-dessus] de tout ce qui a été écrit à propos de l'existence des intellects [séparés] en dehors des textes d'Aristote.

Hillel cite l' attribution à Aristote ${ }^{68}$ en notant plus probable d' attribuer les théorèmes à Platon, avec le plus grand nombre. Cette affirmation ne laisse pas de surprendre, n' ayant de précédent ni chez les commentateurs latins fondamen-

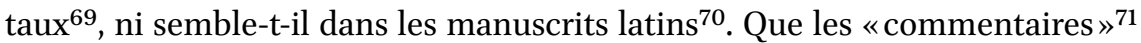
doivent être d'al-Fārābī est plus attendu: la division d'attribution des théorèmes et de leurs développements est constante chez les commentateurs latins jusqu'à ce que saint Thomas ait identifié le modèle fourni par Proclus ${ }^{72}$, la

67 Les numéros sont ceux des 31(32) propositions selon la numérotation habituelle (éd. Pattin, La deumeure de l'être etc.), suivis pour plus de clarté par le numéro d'ordre, parfois divergent, dans le manuscrit (ex.: 10(11)/12). La position des notes est repérée plus précisément, s' il y a lieu, en italiques, par notre traduction française de la traduction hébraïque de Hillel ou, pour des parties manquant dans celle-ci, par la traduction française, La demeure de l'être, et par les numéros des divisions du texte selon l'éd. Pattin.

68 Albert le Grand, De causis et processu universitatis a prima causa, l. II, p. 59a, 61b.

69 Indirectement Thomas d'Aquin, Super Librum de causis expositio, p. 3.

70 À en juger par le Liber de causis, éd. A. Pattin, 1966, p. 13-32 [2000, p. 85-104], qui décrit sommairement quatre-vingt-douze manuscrits (deux cent trente-sept étaient connus de Richard Taylor en 1983) dont aucun ne comporte une telle attribution. Il relève cinq fois l'attribution à Proclus: la proximité des doctrines et des noms aidant, est-ce de là que le traducteur hébreu tire cette attribution? Son travail serait alors postérieur à la découverte de la source proclusienne par saint Thomas (1272).

71 V. supra, n. 10.

72 Thomas d'Aquin, Super Librum de causis expositio, p. 3, l. 3-10; Cf. D'Ancona 1992a, p. 215: 
plus complexe ayant été celle d' Albert le Grand ${ }^{73}$; cependant, Hillel se réfère, dans cette présentation et à deux autres reprises dans ses notes sur le texte, à un livre des Six Principes $^{74}$ qui existe en hébreu ${ }^{75}$ mais non, semble-t-il, en latin ${ }^{76}$. Le traducteur partage en tout cas avec les Latins l' attribution plurielle, signe du sentiment de se trouver en présence d'un écrit de synthèse doctrinale.

1/1a et b. Il n' est pas sûr que ces deux premières notes, disposées dans la marge du manuscrit, à la différence des suivantes, bien que, semble-t-il, copiées de la main du copiste principal, soient dues au même auteur que les suivantes.

1/1a.

תימה: איך איפשר שתקדום פעולת הסבה הראשונה בעלול, טרם שתגיע אליו פעולת

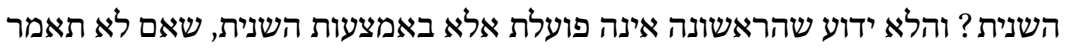

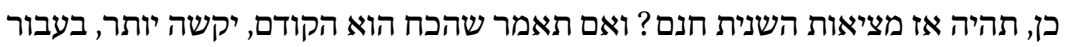

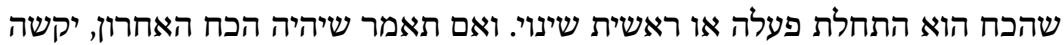

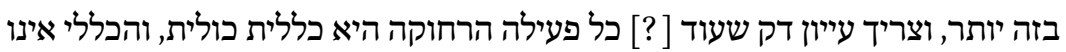

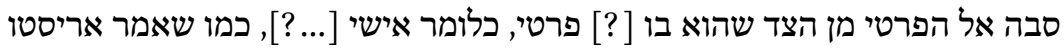

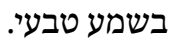

C' est surprenant: comment se peut-il que l'action de la cause première précède dans le causé avant que ne l'atteigne l'action de la cause seconde? N'est-il pas connu que la première n' opère que par l'intermédiaire de la seconde, car si l'on ne dit pas cela, alors l'existence de la seconde est inutile? Et si l'on dit que la puissance est ce qui vient en premier, on est encore plus en difficulté, parce que la puissance est le début de l'action ou le commencement du changement, et si l'on dit qu'elle vient en dernier, c' est encore plus difficile, et il faut faire grande atten-

«Dans les premiers ouvrages consacrés au De Causis, la distinction entre l'auteur des lemmes et leur Commentator est constante».

73 Albert le Grand, De causis et processu universitatis a prima causa, l. II, c. 1, p. 59-61: un ensemble d'énoncés d'Aristote (ou une lettre d'Aristote De principio universi esse) mêlés de matériaux puisés chez Avicenne, Algazel et al-Fārābī, arrangés en théorèmes par le juif David. Les enjeux philosophiques en ont été analysés en profondeur par Libera 199o, p. 354-364.

74 V. supra, présentation, n. 62.

75 v. supra, présentation, n. 63.

76 v. supra, présentation, n. 64 . 
tion. En outre, toute cause lointaine est générale, universelle, et le général n' est pas cause du particulier en tant que particulier, c' est-à-dire individuel $[\ldots \text { ? }]^{77}$, comme a dit Aristote dans la Physique.

L'argument allégué se trouve en plus d'un passage de la Physique: I,9,12: "Quand un animal doit devenir animal autrement que par accident, ce n'est pas de l' animal en général qu'il vient»; II,3 est le chapitre des causes; II,3,12: «les causes et leurs différents genres peuvent être considérés aussi comme agissant indirectement et par accident. Ainsi c' est autrement que Polyclète est cause de la statue, et autrement que le statuaire en est cause (...) Par exemple, on pourrait dire que c' est l' homme qui est cause de la statue, ou même d'une manière encore plus générale que c' est l'être vivant.»; 18: «ce médecin particulier qui guérit existe en même temps que le malade particulier qu' il soigne»; II, 7,6 : «Il y a deux principes qui, dans la nature, peuvent mouvoir les choses; l'un n'est pas du domaine de la Physique, attendu qu'il n'a pas en lui-même l'origine du mouvement; et tel est l'être, s'il en est un, qui peut mouvoir sans être mu, comme le ferait l'être absolument immobile, et antérieur à tous les êtres; l' autre principe, c' est l' essence et la forme, parce que la forme est la fin en vue de laquelle est fait tout le reste.» (trad.J. Barthélemy-Saint-Hilaire). Mais il se trouve surtout en Métaph., $\Lambda$, 5, 1071a: «l' homme a d'abord pour cause ses éléments, savoir le Feu et la Terre, comme matière, et sa forme propre, - puis une autre cause, cause externe, c' est-à-dire le père (...) les causes universelles dont nous parlions n' existent donc pas. Le principe des individus, en effet, c' est l'individu; de l'homme en général ne sortirait que l'homme en général, mais l'homme en général n' est pas; c' est Pélée qui est le principe d'Achille» (trad. J. Tricot).

Cette note réunit trois arguments: 1) si la cause première agissait directement dans le causé, la cause seconde serait inutile, ce qui ressemble à première vue à un paralogisme (car la cause seconde pourrait avoir un effet différent de celui de la cause première) mais qui s' appuie peut-être sur Thomas citant Proclus, Elementatio theologica, 56: Omne quod a secundis producitur, et a prioribus et causalioribus producitur eminentius, a quibus et secunda producebantur, Saffrey, p. $5,1.18-20$, ce qui donnerait à penser que la cause seconde soit seulement plus faible que la cause première; toutefois, l'objection suppose d'ignorer la suite du commentaire de Thomas aussi bien que l' exemple cité par le développement de la proposition (Pattin, §§ 6-11), pourtant figurant peu après le lieu de 
cette intervention dans le texte hébreu; 2) la puissance que possède la matière de la chose, sa prédisposition ${ }^{78}$, n'a pas de place dans le schéma proposé: on ne peut dire qu' elle est première, car elle est le début plutôt que la cause, et l'on ne peut dire qu' elle est dernière (puisque préexistante) ${ }^{79}$;3) l' action lointaine ne rend pas compte des particuliers. Il n' est pas impossible de la retrouver, comme les précédentes, parmi les questions que posent Gilles de Rome ${ }^{80}$ ou Siger de Brabant ${ }^{81}$ et, hors la forme de question, chez Thomas ${ }^{82}$, deux d'entre elles, même, déjà chez Ps. Henri de Gand ${ }^{83}$.

1/b.

קשיא. הדם והליחות הם הסיבה הקרובה, והחומר הקרוב [! צצ'יל הרחוקה] לאברים,

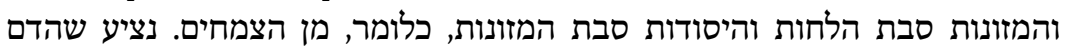

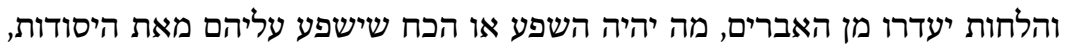

ומה סבה יהיה אליהן? ומדרו מן יחרי

Objection: le sang et les humeurs sont la cause prochaine et la matière, la lointaine ${ }^{84}$, des membres, et les aliments cause des humeurs, et les éléments cause des aliments, c'est-à-dire des végétaux. Supposons que le sang et les humeurs soient absents des membres, quel sera l'épanchement ou la puissance qui épanchera sur eux à partir des éléments, quelle cause s' exercera sur eux?

78 Aristote, Métaphysique, $\Theta(\mathrm{IX}), 1,1046 \mathrm{a}, 10-15$, puissance passive; 6, 1048a, 25-35.

79 Aristote, Métaphysique, $\Theta(\mathrm{Ix}), 8,1049 \mathrm{~b}, 3-5$ : «De nos considérations $(\Delta, 11,1018 \mathrm{~b}$ 9-1019a 14) sur les différentes acceptions de l' antérieur, il résulte clairement que l'acte est antérieur à la puissance» (trad. J. Tricot).

$80 \quad$ v. supra, n. 57.

81 Siger de Brabant, Quaestiones super in Librum de causis, p. 36-41, q. 1, Vtrum causa primaria plus influat et magis sit causa effectus causae secundariae quam ipsa causa secundaria, et q. 2, Vtrum causa primaria naturaliter possit producere effectum causae secundariae sine causa secundaria (qui reçoit une réponse négative); p. 51-55, q. 5, Vtrum forma communior sit prior et forma minus communis sit posterior; q. 6, Vtrum forma magis communis sit magis causa quam forma minus communis; peut-être q. 7 , Vtrum cum aliquod individuum hominis non est remaneat animal.

82 Thomas d'Aquin, Super Librum de causis expositio, p. 9, l. 10-11.

83 (Ps.-)Henri de Gand, Quaestiones in Librum de causis, q. 9 et 10, à propos du déficit de la cause première par rapport à la seconde, éd. Zwaenepoel, p. 33-36; q. 11, que la première ne saurait opérer sans la seconde, p. 37. L'édition date ce commentaire entre 1245 et 1255 (p. 15).

84 L'hébreu porte par erreur: «la prochaine »; ce qui est ici nommé «la matière» correspond à ce qui est appelé «les éléments» dans la suite de cette note. 
On montre ici, sur un exemple médical, la nécessité des causes secondes en tant qu' intermédiaires; cette objection s' ajoute aux trois précédentes.

2. Une note marginale, f. $75 \mathrm{v}$, explique le mot «horizon» translittéré dans le corps du texte (\$22: L'existence qui est après l'éternité et au-dessus du temps est l'âme, parce qu'elle est plus bas que l'horizon de l'éternité et au-dessus du temps) en lettres hébraïques:

פירוש: כמו העג[ו]לה הסוב[ב]ת את מבטינו מכל מה שנוכל לראות. וזה כמו דמיון

Explication: comme le cercle qui circonscrit notre vue de tout ce que nous pouvons discerner, et c'est seulement à titre de comparaison.

3. Une note marginale, f. 76 , après les mots: et ainsi elle [l'âme supérieure] produira une action divine $(\$ 32)$ :

פירוש: בעבור שיש לה, בזו הפעולה של ההנעה, דמיון הכח האלהי, ועם היותה כלי השכל, תעשה פעולה שכלית [! כנראה, עצ'יל אלהית].

«Explication: parce qu'il y a dans cette action de motion une ressemblance avec la puissance divine, bien qu' elle ne soit qu' un instrument de l' intellect, elle opère une action divine», où le copiste, peut-être choqué par l'idée, en tout cas à la faveur d'une ressemblance paléographique entre les deux mots hébreux, a écrit «une action intellectuelle», ce qui ne serait qu'une lapalissade. Cette note ne fait guère plus que répéter le texte; peut-être voudrait-elle résoudre la difficulté due au glissement de la notion d'action «divine» à celle d'action «intellectuelle», éventuellement due à une erreur dans la tradition latine (l'éd. Pattin [\$§32-33] semble témoigner d'un semblable glissement).

$10(11) / 12 / a$.

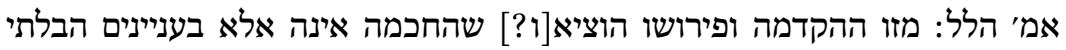

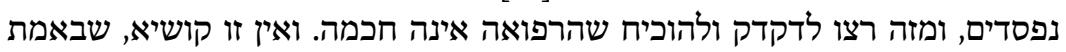

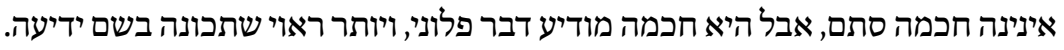

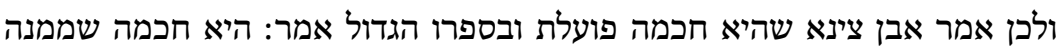

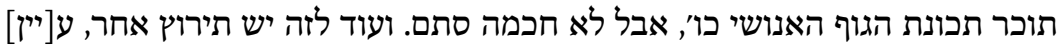


Hillel a dit: de cette proposition [Tout intellect pense les choses perpétuelles qui ne périssent ni ne tombent sous le temps] et de son explication on a tiré qu' il n'y a de science que de ce qui ne se corrompt pas et de là on a voulu faire une distinction et montrer que la médecine n' est pas une science. Il n'y a pas là de difficulté car, en vérité, elle n' est pas une science au sens absolu (stam = simpliciter?), mais science en ce qu' elle donne à connaître quelque chose, et qu'il conviendrait mieux de la qualifier du terme de connaissance. C' est pourquoi Avicenne a dit ${ }^{85}$ qu' elle était une science pratique et dans son grand livre (le Canon) il a déclaré qu' elle «était la science grâce à laquelle on connaissait la disposition du corps humain », etc. ${ }^{86}$, mais non une science tout court; et cela peut se résoudre encore autrement, voir ce [qu' il en a écrit].

Lui-même médecin, Hillel note immédiatement une conséquence bien éloignée du mouvement métaphysique du texte qu'il traduit et étudie.

$10(11) / 12 / b$.

\section{אמנם פירוש זו ההקדמה הוא נגד האמונה ואין לסמוך עליו.}

Cependant l'explication de cette proposition est contraire à la foi et il n'y a pas à s' appuyer sur elle ${ }^{87}$.

Ce jugement porte logiquement sur la partie omise du développement (début du §101), dont n'a été expressément rapportée que la fin («Le commentateur dit à la fin de l'explication, avec force»). Cette dernière glose reprend sans doute Thomas d'Aquin, mais renvoie par là non, comme lui, au théorème (§100: Tout intellect pense les choses éternelles qui ne sont pas détruites ni ne

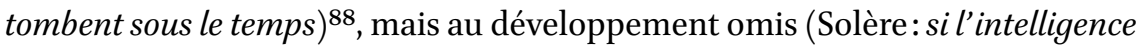

85 Avicenne, Urjûzatfît-tibb («Poème sur la médecine»): «La médecine est [l'art de] conserver la santé et éventuellement de guérir les maladies survenues dans le corps »: Medicina est conservatio sanitatis et curatio aegritudinis... cuius prima divisio est, in theoricam et practicam (Avicenne, Poème sur la médecine, éd. G. Rhau, Wittenberg, 1562, f. A5v).

86 Avicenne, Canon, 1.1.1.1: «La médecine est une science par laquelle on connaît les manières dont le corps humain se comporte et évolue, du point de vue de ce qui est en bonne santé ou de ce qui altère sa santé, en vue de préserver intégralement la santé et de la restaurer, le cas échéant, lorsqu' elle est déficiente».

87 Cette note est inscrite dans le texte (f. $78 \mathrm{r}$ ) parallèlement à la précédente; il se peut que le Amar Hillel qui les précède vaille pour l' une et l' autre.

88 Thomas d'Aquin, Super Librum de causis expositio, p. 73, 1. 4-5: signanter autem dicit 'quae 
est toujours ce qui n'est pas mû, elle est alors cause pour les choses perpétuelles, qui ne sont pas détruites ni changées et ne tombent pas sous la génération et la corruption). On pourrait donc supposer un recours au commentaire de Gilles de Rome, qui conteste le même point que Thomas mais à propos du début du développement (f. 39v) et non du théorème. Contrairement à ce que donne à penser la formule, la partie omise est très brève : « en effet, si l' intellect est ce qui ne se meut pas, il est la cause de choses éternelles qui ne périssent pas et ne sont pas soumises à la génération et à la corruption »; il s' agit peut-être de refuser que l'intellect, et non Dieu même, soit la cause des choses éternelles, autrement dit de refuser une thèse de la création «par l'intermédiaire de l' intellect», d'origine plotinienne, que Cristina D’Ancona a jugée caractéristique du De causis et qui permettait de concilier la causalité par création et la causalité par information ${ }^{89}$. Mais la difficulté s' éclaire autrement par le biais du commentaire de Thomas, auquel la formule de condamnation doit être empruntée ${ }^{90}$, et qui explicite les conséquences ruineuses de cette position: si les productions de l'intellect étaient éternelles, les anges ne pourraient causer d'innovation dans le cours des choses, Dieu moins encore, et le monde serait éternel ${ }^{91}$.

$14(15) / 14$.

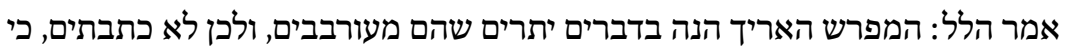

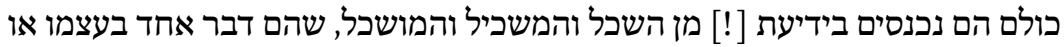

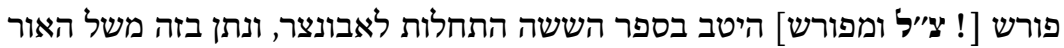
והראות והשמש, ועיין שם. גם רבינו משה באר זה היטב בהשרת השכלת האילן.

La note suit ce passage du Liber de causis $^{92}$ : [\$124. Tout connaissant connaît son existence; aussi fait-il retour vers elle d'un retour total. \$125. (trad. Solère): La raison en est que la connaissance n'est rien d'autre qu'une action intelligible. Lors donc que l'être connaissant connaît sa propre essence, il revient à elle par son

non destruuntur neque cadunt sub tempore', où il s' agit de la fin de la proposition proprement dite; à propos de signanter v. supra, n. 59 .

89 Cf. D'Ancona 1995, p. 73-95.

90 Thomas d'Aquin, Super Librum de causis expositio, p. 74, 1. 25-26: Hac enim probatione suscepta, multa fundamenta catholicae fidei tollerentur. Ce parallèle et celui du signanter précédent avaient été signalés par Steinschneider 1863, p. 111, n. 2.

91 Thomas d'Aquin, Super Librum de causis expositio, p. 74, l. 7-p. 75, l. 2: sequeretur enim quod angeli nihil de novo in his inferioribus immediate facere possent, et multo minus Deus qui non solum est aeternus, sed ante aeternitatem, ut supra dictum est, et sequeretur ulterius mundum semper fuisse.

92 Sont rayées les phrases du texte latin courant omises par le traducteur hébreu. 
opération intelligible. §126. Et cela ne peut être, sinon parce que le connaissant et le connu sont chose une [...] sa substance fait donc retour à son essence. $\$ \$ 127-$ 128. La raison en est la suivante: étant donné que la connaissance est science du

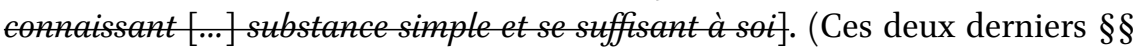
ainsi remplacés dans la traduction hébraïque de Hillel, où se reconnaît encore l'essentiel du §127: Ainsi il le connaît parce qu'il est connaissant et qu'ainsi sa substance revient sur sa propre substance. Et cela advient parce que la connaissance n'est pas autre chose qu'une action intelligente). - «Hillel a dit: le commentateur s'est étendu ici en choses superflues et confuses, c' est pourquoi je ne les ai pas écrites; elles relèvent toutes de la connaissance de l'intellect, de l'intelligent et de l' intelligible qui sont substantiellement une seule chose et c'est bien expliqué dans le livre des Six Principes d'al-Fārābī qui donne à ce propos l' exemple de la lumière, de la vue et du soleil, qu' on s'y reporte ${ }^{93}$; notre maître Moïse [Maïmonide] l'a aussi bien exposé à propos de l'intellection de ces choses ${ }^{94} »$.

L'annotateur ramène ici de manière expéditive l'inconnu au connu sans s'arrêter aux «choses superflues et confuses» qui témoignent peut-être d'une doctrine quelque peu différente de celle de Maïmonide et de ces sources, à en juger par la pluralité de propositions des Éléments de théologie de Proclus que saint Thomas cite ici dans son propre commentaire.

15(16)/15 (après le §129: Toutes les puissances qui sont infinies dépendent du premier infini qui est la puissance des puissances. Non parce qu'elles sont [au pluriel, selon une variante attestée chez Pattin et notée par Solère] fixées dans les choses existantes, mais elles sont dans les choses existantes qui possèdent [de ce fait?] la fixité).

\section{אמר הלל: דברי הפירוש בזה הוא נבוך לבלי צורך, ולכן לא כתבתים.}

Hillel a dit: le propos de l' explication ici s'égare sans nécessité, c' est pourquoi je ne l'ai pas rapporté.

93 Al-Fārābī, Sefer ha-hathalot (éd. Filipowski), p. 4-5: où la métaphore évoquée par Hillel (il s'agit de la manière dont l'intellect agent rend l'homme capable de comprendre à la manière dont le soleil, par sa lumière, rend la vue capable de voir cette lumière même et sa source) est la fin d'un long développement sur la manière dont chaque degré d'intelligence est capable d'intelliger ce qui est au-dessus de lui, par le fait même que celui-ci l' intellige, et les autres intelligibles.

94 Moïse Maïmonide, Le guide des égarés, I, 68, trad. Munk, t. I, p. 301-312. 
Cette note encore confirme l'identité du traducteur et de l'annotateur. Quant à ce qui a pu l'indisposer dans le développement de cette proposition, ce pourrait être cette notion très néoplatonicienne des puissances créées mais infinies: aux §§130-136, il n' est encore question que de l' intellect premier créé, mais au §137 s' affirme à plein, et comme nulle part ailleurs dans l' opuscule, le statut similaire des «bontés simples telles que la vie et la lumière», intermédiaires de l'effusion à partir de la Cause première qui portent atteinte à l'idée de la création une et directement opérée par Dieu seul.

16(17)/16 (après les $§ \S 138-142$ : Toute puissance unifiée est plus infinie que la puissance multiple, etc.).

אמר הלל: הגירסה זאת מן ההקדמה וגם פירושה אינם נכוחים, וזהו בעבור שהוא נותן

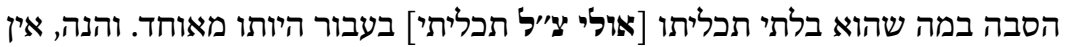

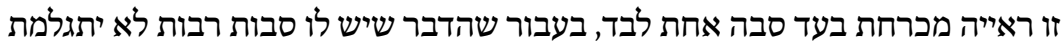

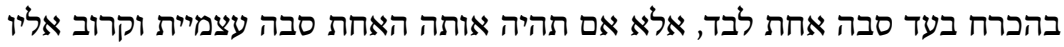

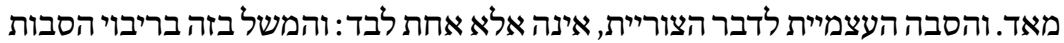

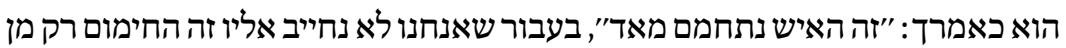
צד ההתקרב אל האש, ואומרים: "אם נתחמם, אם כן קרב אל אל האבור האשי", בעבור שאפשר

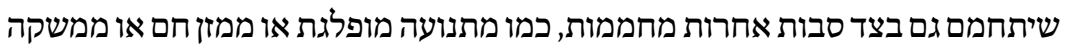

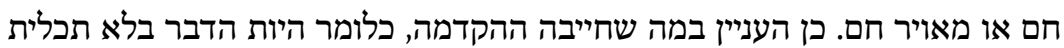

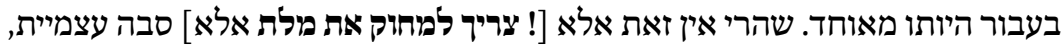
כי איפשר שיהיה לא תכלית בעבור היותו ראשון לכל הנמצאים, שכל מה שהוא ראשון

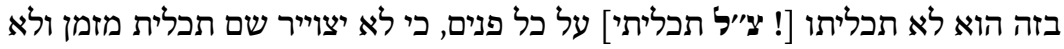

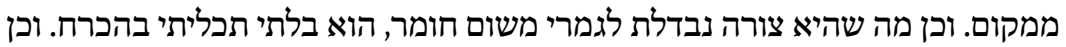

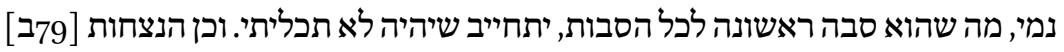

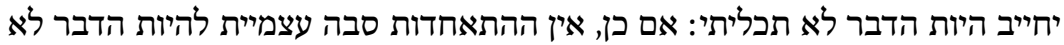

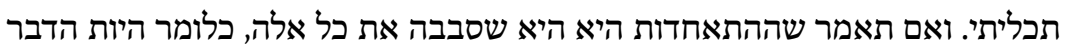

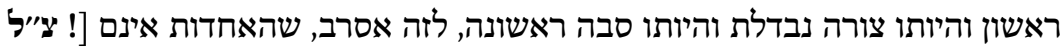

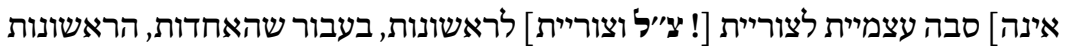
והאחד והראשון הם מתהפכים בנושא זה לזה: שכל מה שהוא אחד פשוט בתות לתכלית לרית

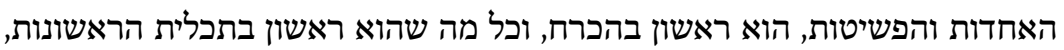

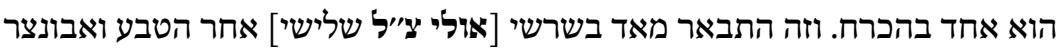

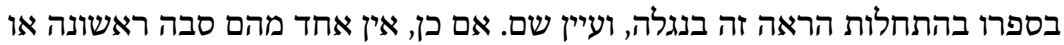

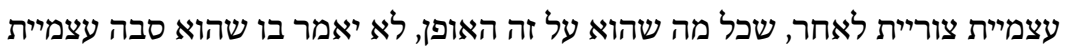

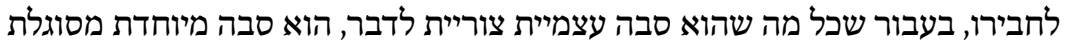

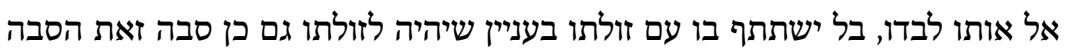

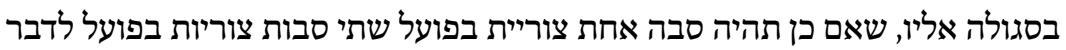

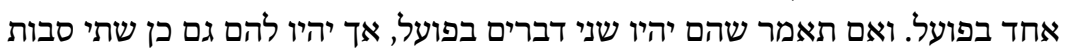

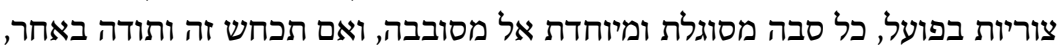


יולד מזה שנאמר שיהיה איפשר היות עצם אחד בפועל בעל שני עצמים בפועל, ושיהיה

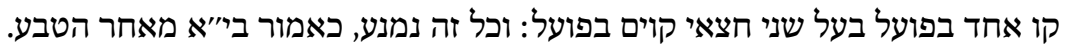

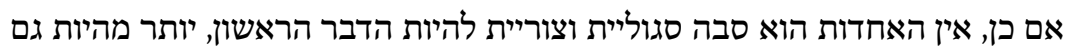

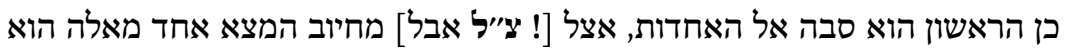

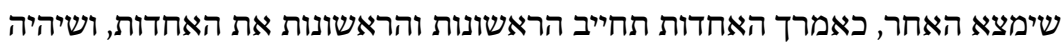

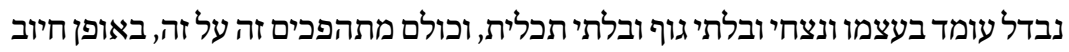

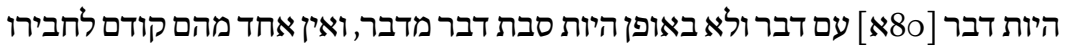

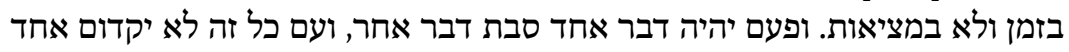

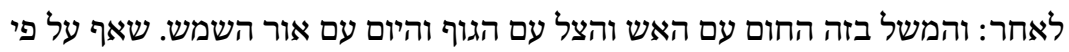

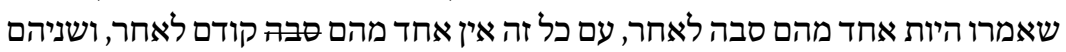

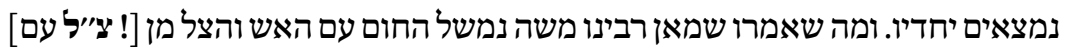

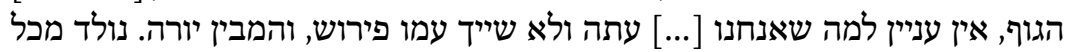

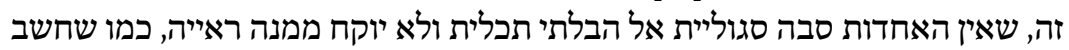

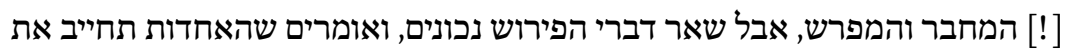

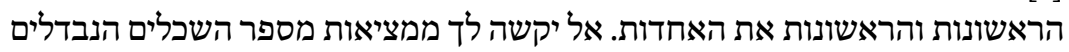

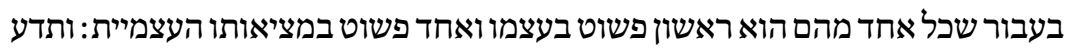

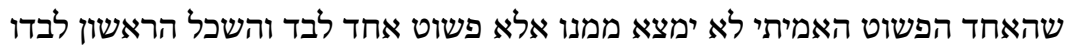

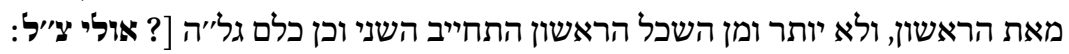
[עד] גלגל התחתון].

Hillel a dit: cette version de la proposition ainsi que son commentaire ne sont pas justes. Il (!) donne en effet comme cause de l'infinité [d'une puissance] son unité et ce n' est pas une preuve nécessaire, car une chose qui a des causes multiples ne prend pas corps nécessairement à cause d'une seule, à moins qu' elle ne soit essentielle et cause très proche de cette chose. Et la cause substantielle de la chose, [et] qui [lui] est formelle, est unique. L'exemple, à cet égard, de la pluralité des causes est si l'on dit que tel homme a très chaud en n' attribuant cette chaleur qu'à sa proximité du feu ${ }^{95}$, disant que s'il a chaud, c' est qu'il est près du feu; or, il se peut qu'il ait chaud pour d'autres causes échauffantes comme un mouvement exagéré, une nourriture chaude, un breuvage chaud, un air chaud. Il en va de même de cette causalité posée par la proposition, à savoir que la chose soit infinie par suite de son unité, alors que ce n' en est que [! scil.: ce n'en est pas] la cause essentielle, car il se peut qu' elle soit infinie parce qu' elle est première de tous les existants, car tout ce qui est premier en cela est infini, car on ne s' en figure pas la fin dans le

95 Élaboration à partir de l' exemple du feu, source de toute chaleur, donné dans le commentaire de saint Thomas à la prop. 17(18), éd. Saffrey, p. 102, l. 7-8. 
temps ni dans l' espace; de même ce qui est forme entièrement séparée de toute matière est infini nécessairement; de même encore ce qui est cause première de toutes les causes est nécessairement infini; de même l'éternité (f. 79v) implique que la chose soit infinie. Ainsi, l' unité n' est pas cause essentielle de l'infinité de la chose. Et si l'on dit que l' unité est justement ce qui a causé tout cela, c' est-à-dire que la chose soit première, qu' elle soit une forme séparée et qu' elle soit cause première, je refuse [en répondant] à cela que l'unité ne sont (sic) pas cause essentielle et formelle pour la primauté, parce que l'unité et la primauté et l'un et le premier sont substituables (mithafekhim) dans un sujet l' un à l' autre; car tout ce qui est un [et] simple d' une unité et d'une simplicité absolues est nécessairement premier, et tout ce qui est absolument premier est nécessairement un, ce qui est très bien expliqué au l. III de la Métaphysique ${ }^{96}$; al-Fārābī, dans son livre des Principes, l'a montré clairement, qu'on s'y reporte ${ }^{97}$. Dans ces conditions, aucun d'entre ces [principes] n' est cause première ou essentielle-formelle d' un autre; car tout ce qui est de la sorte, on ne dira pas qu'il est cause essentielle de l' autre, car tout ce qui est cause essentielle-formelle d' une chose est une cause particulière, propre à elle seule, associée avec rien d' autre de sorte que cette cause serait aussi sa cause particulière, car alors une seule cause formelle en acte en serait deux pour une seule chose en acte. Et si l'on dit qu' il y a deux choses en acte mais qu' elles ont aussi deux causes formelles en acte, chaque cause [étant] propre et particulière à son causé, ou si l'on nie cette [dernière proposition] et que l'on affirme l'autre, il en résultera que nous dirons qu'il sera possible qu'une seule substance en acte comporte deux substances en acte et qu' une droite en acte comporte deux demi-droites en acte, et tout cela est impossible, comme il est dit au l. xi de la Métaphysique $^{98}$. Dès lors, l'unité n' est pas plus la cause particulière et formelle de la primauté d'une chose que sa primauté n' est elle-même cause de

96 Si notre correction de la leçon pourtant plausible elle-même du ms., šoršey («les principes»), en šeliši («le [l.] III») est justifiée. La référence pourrait être alors à B (III) 999ab ou 10o1ab où il est question plusieurs fois du caractère premier de l'un.

97 Éd. cit., p. 1, mais qui formule l'implication inverse: «ce qui est premier ne peut être pluriel, mais seulement un et simple» (אחפומה שבמדריגה הראשונה אי אפשר שיהיה הרבה אלא). אחד פשוט לבד

98 Aristote, Métaphysique, K(xI), 2, 106ob 5 sqq., sur la critique de ceux qui identifient le premier principe à l' un; 10,1066b 10 sqq., sur la non-divisibilité de l' infini en acte (muettement informé par la demi-droite en puissance dans la droite entière, Métaphysique, $\Theta(\mathrm{VIII})$, 1048a 30-35 et peut-être par l' exemple des deux demi-droites en Aristote, Physique, viII, 12 , 10 sqq., en part. 25$)$. 
[son] unité, mais c'est la présence de l'une qui rend l'autre nécessaire; pour ainsi dire, l'unité implique la primauté et la primauté, l'unité, et que [celui qui les possède] soit séparé, subsistant par lui-même, éternel, sans corps, sans limite, et tous [ces attributs] sont substituables l'un à l' autre selon le mode de la nécessité que l' un (f. 8or) accompagne l' autre, et non selon celui de la causalité de l'un par rapport à un autre. Et l'un n'est pas antérieur à l' autre dans le temps ni dans l' existence; quelquefois une chose sera cause d'une autre, sans pour autant que l' une soit antérieure à l' autre, à l' exemple de la chaleur avec le feu, de l' ombre avec le corps et du jour avec la lumière du soleil: bien que l'on dise que l'un est la cause de l' autre, néanmoins l'un n' est pas antérieur à l' autre et tous deux existent ensemble ${ }^{99}$. Et pour ce qu'on a dit ${ }^{100}$ que notre maitre Moïse (Maïmonide) avait refusé la comparaison ${ }^{101}$ de la chaleur avec le feu et de l' ombre avec le corps, ce n' est pas ce dont nous [traitons] à présent et il n'y a pas lieu de le commenter; qui réfléchit le reconnaîtra. De tout cela résulte que l'unité n' est pas cause particulière de l'infinité et qu' on n' en tire pas non plus une preuve [de celle-ci] comme l' ont pensé l' auteur et le commentateur; mais le reste du commentaire est juste en disant que l'unité nécessite la primauté et la primauté, l' unité. Qu'on n' objecte pas à partir de l' existence d' une pluralité d' intellects séparés, parce que chacun d'eux est premier et simple en sa substance et un et simple en son existence essentielle; qu'on sache qu'à partir de l'un simple véritable rien n' existe que de simple et un, et le premier intellect seul à partir du Premier, rien

99 Cf. Moïse Maïmonide, Le guide des égarés, I, 53, t. I, p. 205-216 (ch. 51-6o, p. 182-266), sur ce que les attributs ne sont pas séparés en Dieu mais ne font que décrire pour les hommes les actions diverses procédant d' une vertu unique. Il en résulte évidemment l' absence de dépendance de l'un par rapport aux autres. C' est peut-être de ce même refus de distinguer en Dieu des attributs essentiels que Hillel tire l' objection rapportée ensuite au nom de Maïmonide contre la métaphore du feu et du chaud qui, comme il le dit, ne regarde pas la présente question d'une éventuelle hiérarchie des attributs.

100 Nous traduisons comme si Hillel évoquait, en employant un hendiadys, une position de Maïmonide qui pourrait sembler une objection; il ne parait pourtant pas entièrement exclu que le texte, qui dit littéralement «pour ce qu'ils ont dit que Maïmonide avait refusé», réponde ici à un adversaire invisible, un autre expositeur juif du Liber de causis (Mä̈monide ne se réfère évidemment pas au Liber) ou quelque contradicteur déjà affronté sur le même sujet hors référence au De causis. - L'objection contre ces métaphores au nom de Maïmonide peut provenir soit de son refus de distinguer des attributs d' essence en Dieu (v. note précédente), soit de son refus de toute ressemblance entre lui et les choses (I, 55, t. I, p. 225-226) au profit des seuls attributs négatifs (I, 58, t. I, p. 24O-247); mais Maïmonide n'a pas lui-même employé ces comparaisons.

Ce terme fait difficulté: il désigne d'habitude le terme comparé, non la comparaison. 
de plus; et que du premier intellect suit nécessairement le second, et tous de même [jusqu'à la sphère inférieure] ${ }^{102}$.

Cette note a été suffisamment commentée dans la présentation générale et dans les notes de bas de page précédentes.

17(18)/17a. Résume les $\S \S 144$ et 148, premier et dernier, du développement de la proposition (qui énonce, au §143: Toutes les choses ont une existence, c'est-àdire une essence, du fait de l'existant premier, et toutes les choses sont vivantes et se meuvent du fait de son existence et de sa vie ${ }^{103}$, et toutes les choses intellectives possèdent la science du fait du premier intellect):

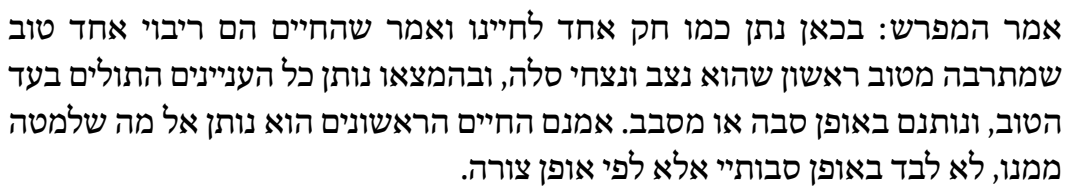

Le commentateur [des théorèmes] a dit: ici, il a donné comme une définition unique à notre vie, en disant que la vie est la multiplication d'un bien qui se multiplie à partir du Bien premier qui est fixe et perpétuel à tout jamais et qui par son existence dispense tout ce qui dépend du bien, à titre de cause ou de cause de cause; cependant, il donne la vie première à ce qui est en-dessous de lui non seulement de manière causale mais [aussi] de manière formelle.

Nous voyons ici un indice de ce que ce type d'intervention est le fait de l' auteur des notes critiques: en effet, ce résumé évite avec soin les formules que la note suivante va mettre en question et insiste d'avance sur la distinction qu'elle va avancer, en énonçant que d' un Bien premier immuable procèdent tous les biens, parmi lesquels la vie, dont le nom (un pluriel, en hébreu) indique luimême le processus de dispensation par l'Un parmi la multiplicité des choses créées.

102 Lecture conjecturale et peu sûre: «et tous de même» est suivi d'un acronyme g.l.h. qui peut se lire galgal ha-tahaton, «la sphère inférieure», mais la préposition alors nécessaire ('ad, «jusqu'à») ne figure pas.

103 Semble supposer dans le modèle latin, au lieu de «et res vivae omnes sunt motae per essentiam suam propter vitam primam», «et res vivae omnes et motae per essentiam suam propter vitam suam», variantes non signalées par Pattin et par Magnard et alii. 
17(18)/17b. Ajoute ce commentaire critique:

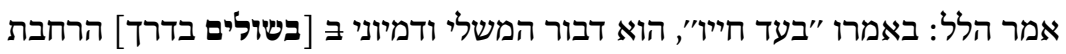

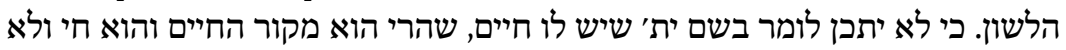

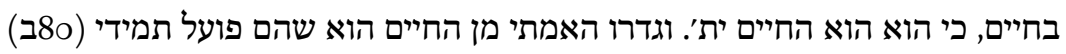
מנפש בגוף מנופש, ויש לחיים גם כן גדרים אחרים.

Hillel a dit: lorsque [le commentateur] énonce «à cause de (bacad) sa vie», c' est une façon de parler en parabole et en figure, en un sens large, car il n'y a pas lieu de dire, à propos de Dieu, qu'il possède une vie, car il est la source de la vie et il est [le] vivant (hay $)^{104}$ et non dans la vie; il est lui-même la vie. La vraie définition de la vie est d'être une action permanente (8ov) d'une âme sur un corps animé105; la vie a encore d' autres définitions.

Hillel introduit une distinction entre vie divine et vie humaine, la première étant ainsi nommée de manière figurée, conformément à la distinction et à la formulation maïmonidiennes ${ }^{106}$, mais peut-être, ici, réactivées à la lecture du commentaire de saint Thomas ${ }^{107}$. À cela il oppose la définition «vraie», c'està-dire au sens propre, de la vie, qui suppose la présence d'un corps (d' après le De anima?), ajoutant qu'il en est d' autres (médicales?). Il identifie décidément la Cause première à Dieu ${ }^{108}$.

104 Cet adjectif a la particularité d' avoir par rapport au nom de la vie l' apparence morphologique d'un singulier par rapport à un pluriel; ainsi il apparaît plutôt comme son principe unitaire que comme son dérivé. Hillel se souvient sans doute aussi de la mise en garde de Maïmonide contre l'idée d' attributs de Dieu (v. supra, prop. 16 [17]), répétée par lui précisément à propos de son caractère de «vivant» (par essence), et non «doué de vie», Moïse Maïmonide, Le guide des égarés, I, 68, t. I, p. 302-303.

105 Cf. Aristote, De anima, II, 1, 412a12-412b, 413a1o?

106 Moïse Maïmonide, Le guide des égarés, I, 57, t. I, p. 232, à propos des supposés attributs d'essence: «il est toujours d'une existence nécessaire [...] il existe, mais non par l' existence, et de même il vit, mais non par la vie, il peut, mais non par la puissance, et il sait, mais non par la science».

107 Thomas d'Aquin, Super Librum de causis expositio, p. 102, l. 4-24, en part. 16-17, citant Proclus (Elementatio theologica, 102): Omnia viventia suiipsorum motiva sunt propter vitam primam.

108 Se conformant en cela au Livre des principes d'al-Fārābī, éd. cit., p. 1: «du premier, il convient de croire qu'il est Dieu, et il est la cause première, [cause] prochaine de l' exis-

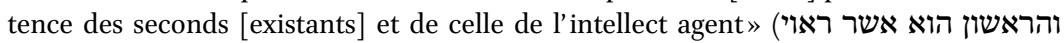
(שיאמן בו שהוא האל והוא הסבה הראשונה הקרובה למציאות השניים ומציאות השכל הפועל (2). 
18(19)/18 (après le §149: Parmi les intellects, il y a l'intellect divin, ceux qui reçoi [ven]t des biens premiers divins qui proviennent de la Cause première, d'une réception abondante; et les intellects simples, etc.).

אמר הלל: ההקדמה הזאת לא צריכה פירוש.

Hillel a dit: cette proposition ne requiert pas d'explication.

Aussi en a-t-il omis le développement ( $§ 150-154)$.

19(20)/19 (après le §155: La Cause première régit toutes les choses créées sans se mêler aucunement à elles).

אמר הלל: זו אינה צריכה פירוש.

Hillel a dit: celle-ci ne requiert pas d'explication.

Et il a omis les $\S \S 156-161$.

20(21)/20 (après le $§ 162:$ Le Premier est pour ainsi dire riche par lui-même et il n'est pas de richesse supérieure à la sienne).

אמר הלל: גם זה הדיבור משלי: באומרו "עשיר ועושר"ירצה בו משפיע שפע.

Hillel a dit: c' est là encore une expression figurée: par 'riche' et 'richesse' on veut dire 'celui qui épanche' [et] 'épanchement'.

Cette remarque le dispense apparemment de traduire le développement $(\$ \S 163-165)$.

$21(22) / 21$.

אמר הלל: זאת גם כן אינה צריכה פירוש.

Hillel a dit: celle-ci non plus ne requiert pas d'explication.

Il a amalgamé, pour formuler la proposition, le $§ 166$ et le début du $§ 167$ en ajoutant encore la notion de cause qui ne figure pas (La cause première est plus haute que toutes les causes et que tous les discours et ne connaît ni augmentation ni diminution); il omet la suite du développement jusqu' au §171 inclus. 
22(23)/22 (après le § 172: Tout intellect divin connait les choses parce qu'il est un intellect et les dirige parce qu'il est divin).

גם זאת ידוע. רצה בה להודיע באיזה אופן הוא (81א) משכיל ובאיזה הוא מנהיג.

Cela aussi est connu. Il a voulu faire connaître de quelle façon [l'intellect divin] intellige et régit.

Omission des $\S \S 173^{-175}$.

23(24)/23a ( $\$ 176:$ La Cause première est en toutes choses selon une disposition unique).

פירוש: לפי תכונה, נותנת ומשפעת כל הנמצא. ובזה האופן, ימצא כחה בכל העניינים

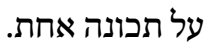

Explication: selon [sa] disposition, donne et épanche tout l'existant. De la sorte, sa puissance se trouve en toutes choses selon une disposition unique.

$23(24) / 23 \mathrm{~b}$ (suite: mais toutes choses ne sont pas en elle selon une disposition unique).

פירוש: כי הם עומדים ומתקיימים בעבורה רק לפי כח הכנת הקבלה במקבל ולא לפי אופן הנותן, שאם כן היו כלם דומים אליה בטובותיהם.

«Explication: [les existants] se maintiennent à cause d'elle, [mais] seulement selon la capacité de traiter ce qu'il reçoit qui se trouve dans le receveur, et non selon le donateur, car alors tous seraient semblables à elle [la Cause première] quant à leurs biens.» - Les $§ \S 177-180$ ne sont pas traduits.

$23(24) / 23 c$. Remarque sur la plus grande appropriation à celle-ci du développement d' une autre proposition, non précisée. Il pourrait s' agir de la prop. 19(20), dont le développement avait été jugé superflu par l' annotateur: « La cause première dirige toutes les choses créées sans aucunement se mêler à elles»; le développement visé serait alors celui des $§ \S 156-161$.

ונראה לי שאותו הפירוש שפירש המפרש בהקדמת [!] היה יותר ראוי שיפורש בזו. 
Il me semble que l'explication donnée par le commentateur à la proposition [l' incipit ou un numéro sont omis] aurait été plus appropriée à celle-ci.

11(12)/24 (après le §103: De tous les premiers, certains sont en d'autres de la manière dont l'un [peut?] être en un autre).

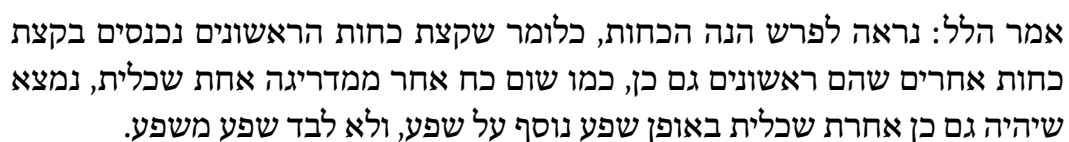

Hillel a dit: il semble qu' on doive expliquer ici les puissances en disant que certaines puissances premières entrent dans certaines autres puissances qui sont aussi premières; à la façon dont, [pour] une puissance quelconque d'un degré intelligible, il s' en trouvera aussi une autre, [également] intelligible, sur le mode d'un épanchement supplémentaire [spécifique?] et non simplement d' un épanchement d' un épanchement.

On peut se demander dans ce cas particulier si Hillel remplace ici délibérément le texte du développement ( $§ \S 104-108)$ ou s'il n' en disposait pas (la proposition, déplacée, ayant pu être copiée sans lui en marge d'un modèle ou être saisie à la hâte à partir d' un autre manuscrit). Qu'il n' en dise mot et se montre hésitant sur l' objet de la proposition («il semble») irait dans le sens de la deuxième hypothèse. Cependant, le déplacement de cette proposition ici ne doit rien au hasard, comme il ressort des notes de Hillel lui-même à propos de celle-ci et de la suivante; mais il n'est pas possible de déterminer si le réarrangement est de son fait ou avait déjà été opéré dans son modèle latin. D'un autre côté, il est notable qu' alors que l'énoncé seul de la proposition (qu'une faculté est dans une autre selon le mode de celle-ci) n' évoquait qu' une sorte de convertibilité mutuelle, Hillel introduise l' idée de hiérarchie qui figurait bien dans le développement originel, comme s'il avait eu accès bel et bien à celui-ci. En insistant en termes d'influx sur la particularité de chaque mode de présence d'une puissance en l' autre et en écartant l'explication par le seul influx d'influx, Hillel pourrait cependant faire écho à la fin du commentaire de Thomas (Saffrey p. 81, 1. 10-12, mais en termes de similitudines et species), soit plus sûrement à Gilles de Rome (f. 4iv, qui marque plus nettement la hiérarchie descendante que suppose l' «épanchement d'épanchement» dont parle Hillel et qui emploie fluunt). Le terme de «puissances» lui est propre, Thomas et Gilles parlant ici d' «intelligences». Il prendrait position personnellement sur un caractère de cette hiérarchie: elle ne serait pas dégressive par déperdition 
à partir d'un épanchement unique, mais progressive, par enrichissement de l'influx premier par un apport propre des causes secondes. Ce pourrait être la continuation de la critique de la proposition 1: le particulier ne serait pas plus pauvre que le général, mais plus riche que lui.

$24(25) / 25$ (après le § 181: Les substances unes intellectivesn'adviennent pas à partir d'autre chose).

פירוש "מדבר אחר": זולת שכל או נותן שכל בעצם זו מוסף על שכל. וזו דומה לאחרת, וכמעט היא כמו הבדל אחד לכלל ההוא ומפרש אות שותו.

C' est-à-dire d' autre chose qu'un[e substance] intellect[ive] ou le donateur d'un surplus d'intelligence dans cette substance [intellective]. Cette proposition ressemble à l'autre [sic, scil. la précédente], [formule] presque comme une différence [= exception?] par rapport à ce principe, et l' explique.

Noter la continuité avec la note de la proposition précédente. - L' «autre substance intellective» et le «donateur d'intelligence» (Dieu?) se reconnaissent dans la «cause » évoquée par le développement originel (\$185: Et non fit causa formationis suae et sui complementi nisi propter relationem suam ad causam suam semper), comme l' exprimait plus clairement le développement de la prop. $11(12) / 24$ faisant référence à la hiérarchie des intelligences dont on parle. L'idée de la proposition et de son développement serait selon Hillel qu'une substance intelligible, quoiqu' indépendante de tout ce qui est à son niveau et inférieur à lui, est dans un rapport de dépendance causale vis-à-vis d' un autre intellect et, au-delà, de la source des intellects, et que cela mérite explicitation.

25(26)/26 (après le § 187: Aucune substance qui subsiste par elle-même ne tombe sous (a corruption).

פירוש: ואם כן, אינו נהווה מדבר. וזו היא כמו חתימה אל האחרת.

Commentaire: ainsi, elle n' advient pas [non plus] à partir d' autre chose. C' est comme une conclusion de l'autre [sic; scil., la proposition précédente].

Manque à nouveau le développement (\$§ 188-19o). Il n' est peut-être pas nécessaire d'assigner à une référence précise et tacite (Aristote, De generatione et corruptione, I, 3 ?) la notion philosophique banale qu' une chose naît du dépé- 
rissement d' une autre, et réciproquement, qui autorise l' annotateur à renvoyer de la non-corruption à la non-génération et retrouve l' énoncé de la proposition $24(25) / 25$.

26(27)/27 (après le §191: Toute substance périssable et non éternelle est soit composée soit portée par autre chose).

\section{פירוש: זו גם כן היא כמו הבדל אל האחרת, כלומר מן הדבר שאינו נהווה: כי זה שאמר

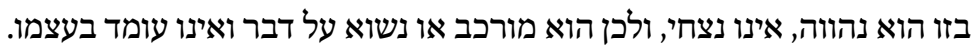

Commentaire: ceci aussi est comme une différence par rapport à l' autre [la proposition précédente], c' est-à-dire [le cas de] la chose [substance] non engendrée, car celle dont il parle dans celle-ci est engendrée et non éternelle, elle est donc composée ou portée par quelque chose et non subsistante par soi.

Omet et résume le développement ( $§ 192-193)$ en reprenant les deux formes de dépendance que celui-ci évoque ( $\$ 192$ : aut est indigens rebus ex quibus est et est composita ex eis, aut est indigens in fixione sua et sua essentia deferente. Cum ergo separatur deferens eam, corrumpitur et destruitur) et en précisant la différence ainsi marquée par rapport aux substances éternelles dont il a été question plus haut.

28(29)/29 (après le §199: Toute substance simple subsiste par elle-même selon son essence [hawayato]).

אמר הלל: נראה לי שאלה שתי הקדמות הם כמו אחת, בעבור שהם מתהפכות זו לזו.

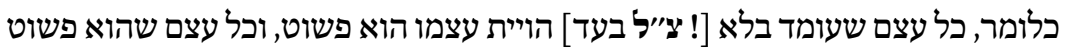

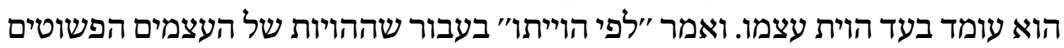

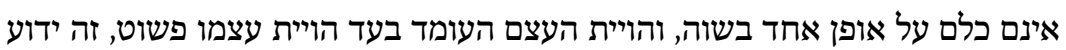
מאד, בעבור שהואיל והוא עומד בעצמו, אין שם הרכבה ולא נשיאות על דבר שם שבם

Hillel a dit: il me semble que ces deux [dernières] propositions ne sont qu' une, étant l'inverse l'une de l'autre, c' est-à-dire que toute substance qui subsiste à cause de (ba'ad) l'essence ${ }^{109}$ de sa substance est simple et que toute substance simple subsiste à cause de l'essence de sa sub-

109 Hawwayah, qui traduisait plus haut generatio, traduit cette fois, dans le texte même de la proposition, essentia. 
stance. [Le texte] a dit «selon (lefi) son essence» parce que les essences des substances simples ne sont pas toutes d'un même mode, à égalité, et que l' essence de la substance qui subsiste par sa propre essence simple, c' est bien connu, subsistant d' elle-même, ne comporte ni composition ni dépendance d' autre chose qui la fasse subsister.

Hillel semble forcer le sens de la proposition, qui portait per essentiam suam, «par» son essence, et non, «selon », c' est-à-dire en fonction des différences entre les essences. Il le fait dans l' esprit du corps du développement, qu' il n'a pas traduit ( $\S 200-202)$; non plus que celui $(\S \S 195-198)$ de la prop. précédente (§194: Toute substance qui subsiste par son essence est simple et non divisée), lequel oppose en effet, à nouveau, les substances subsistantes par leur essence à celles qui sont generatae ex aliquo (§201), mais contre le sens de la proposition et de la conclusion du développement, qui n'introduisent nulle division parmi les substances subsistantes par leur essence. Cette différence s'éclaire au vu du commentaire de Thomas, p. 134, l. 8-10, citant Proclus (où l' on trouve secundum suam substantiam, au lieu du per substantiam du De causis); Thomas opère aussi le rapprochement avec la proposition précédente (ibid., l. 1: Hic ponitur propositio conversa [= mithafekhoth] prioris). Toutefois, alors que Thomas oppose des substances dépendantes du temps et d'autres, subsistantes par soi, Hillel s' en tient à l'opposition plus générale entre substances par soi et substances dépendantes d'autre chose.

29(30)/31 (après le $\S 203:$ Toute substance créée dans le temps ou est toujours dans le temps et le temps ne l'excède pas, ou n'est pas toujours dans le temps et le temps l'excède parce qu'elle est créée dans certains moments du temps).

אמר הלל: זה מבואר.

Hillel a dit: c' est évident.

Le substantiel développement (§§ 204-209) est omis.

$30(31) / 31$ (après le $\S 210$ : Entre la chose dont la substance est dans un instant de l'éternité et la chose dont la substance et l'action sont dans un instant du temps ily a un intermédiaire: celle dont la substance est dans un instant de l'éternité et l'action dans un instant du temps).

אמר הלל: אותו האמצעי [!] הם האמצעיים שהם בין העולם הנצחי והעולם הנהווה

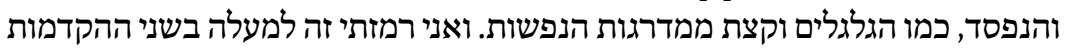
שמתחל]י[ת מן "השכלים" וכו'. 
Hillel a dit: cet intermédiaire, ce sont (sic) ceux qui se trouvent entre le monde éternel et celui de la génération et de la corruption, comme les sphères et certains des degrés des âmes. J'y ai fait allusion dans les [scil. à propos des] deux propositions qui commencent par 'Parmi les intellects', etc. ${ }^{110}$.

Cela peut faire écho au commentaire de Thomas (p. 141, l. 10-p. 142, l. 3) qui envisage successivement cette position intermédiaire pour le corpus caeleste et pour l'âme; toutefois, Thomas conclut à propos du premier qu' il ne relève que du temps; et, quant à la seconde, il ne formule pas de restriction à « certains degrés».

31(32)/32a (après le début du § 214: Ily a une substance qui tombe selon certaines de [ses] dispositions et qui est ( $\mathrm{sic}$ ) sous l'éternité et ily a une substance qui tombe selon certaines dispositions et qui est (sic) sous le temps).

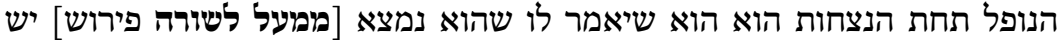 באמת, והנופל תחת הזמן הוא אותו שהוא מציאות באמת, והיש וההואיה הם בזיה בזמן אחד}

Celui qui tombe sous l'éternité est celui dont on dit qu'il est existant, (c'est-à-dire), permanence, véritable et celui qui tombe sous le temps est celui qui est existence véritable; et la permanence et le devenir sont en même temps dans sa $($ sic $)$ substance.

Hillel, sans le dire, ou peut-être son modèle latin, résume lui-même le long développement de la proposition 32 en quelques mots qui identifient bien l'objet de la proposition, à savoir la co-existence de l' existence absolue, éternelle, et de l'existence en devenir, dans le temps, que l'énoncé de la proposition même, dans sa traduction ou dans le modèle de celle-ci, avait rendu inintelligible ${ }^{111}$; le rétablissement se fait au prix d' une rupture dans la phrase

110 Il y en a trois: prop. 9(10), numérotée 14 dans le ms. de Hillel (f. 77v), et prop. 10(11) (num. 12; f. $78 \mathrm{r}$ ), entre lesquelles s' insère la prop. 12(13), bien que numérotée 11 dans le ms. (f. $77^{\mathrm{v}-}$ $78 \mathrm{r}$ ). 9(10) seulement présente un commentaire (supra) en rapport allusif avec le point considéré, Hillel ajoutant que les intellects reçoivent l'épanchement de la Cause première, chacun selon ses capacités; 10(11) ne comporte pas de commentaire ni de glose, 12(13) présente, on l'a vu, une brève notation sans rapport.

יש עצם שנופל בקצת התכונות והוא תחת הנצחות, ויש עצם שנופל בקצת תכונות והוא תחת 111 הזמן; v. supra la traduction du §214. 
de commentaire, qui semble parler d' abord de deux choses distinctes puis de la substance unique qui porte les deux modalités de l' existence, éternelle et dans le temps. Une intervention personnelle, comme d'habitude plus critique, fait suite à cette explication anonyme:

$31(32) / 32 b$.

אמר הלל: איפשר לומר שזו האחרונה היא כמו פירוש אל אותה שלמעלה, ובא לפרש

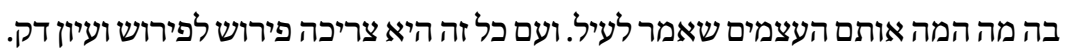

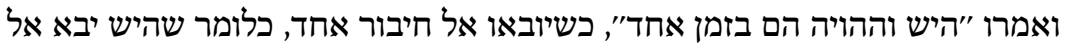

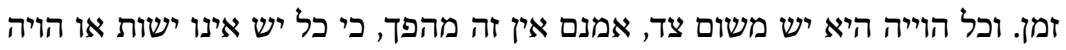

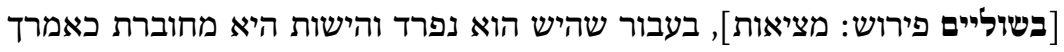

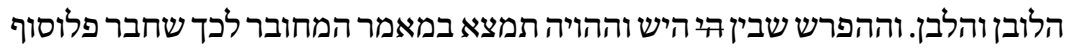

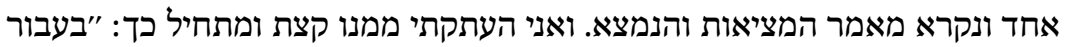

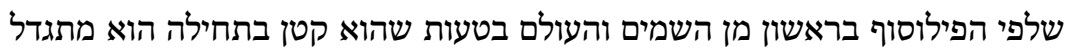

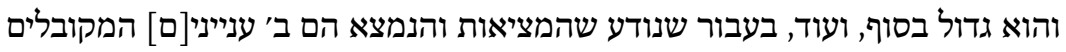

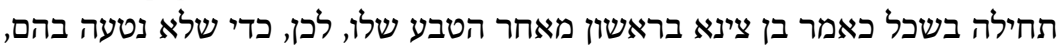

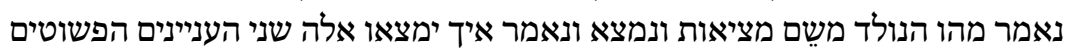

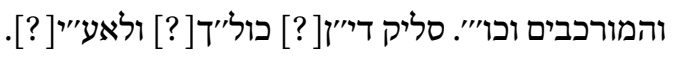

Hillel a dit: on peut dire que cette dernière [proposition] est comme une explication de celle qui se trouve supra, venant expliquer ce que sont ces substances qu'il a dites plus haut; pourtant elle requiert une explication de l'explication et une attention précise. Quand il dit que l' existant [en soi; autrement dit: l' essence] et la génération [l'engendré] sont dans un seul temps [cf. § 214: est ens et generatio simul], [c' est] quand ils sont réunis en un seul composé, c' est-à-dire que l' essence vient dans le temps; tout devenir est essence par quelque côté; cependant la réciproque n' est pas vraie, car toute essence n' est pas existence (yešuth) (dans la marge: c' est-à-dire existence [meșiuth]) ou devenir, parce que l' essence est séparée et l' existence est subordonnée [= accidentelle], comme lorsqu' on dit le blanc et la blancheur. Et la différence qu'il y a entre l'existant et la génération se trouve dans le texte écrit à ce sujet qu'a écrit un philosophe, intitulé De l'existence et de l'existant. J' en ai traduit quelque chose et il débute ainsi: «Parce que, selon le Philosophe au premier livre du Ciel et du monde, d' une (sic) erreur petite au début, elle s' agrandit et se trouve grande à la fin, et encore parce que nous savons que l' existence et l' existant sont les deux choses reçues d' abord dans l' intelligence, comme l'a dit Avicenne au l. I de sa Métaphysique, pour cela, afin qu'on ne se trompe pas à leur sujet, nous exposerons ce qui s'infère (nolad) du 
nom d'existence et [de celui] d' existant et nous expliquerons comment se trouvent ces deux entités, simples et composées [avec d'autres]» ${ }^{112}$, etc.

Le lien établi avec la proposition précédente est analogue à celui qu' opère Thomas, p. 143, l. 1-p. 144, l. 3, par l' intermédiaire de la prop. 107 de Proclus. Le long développement sur le Premier participé et non participant est parallèle à celui de Thomas, p. 144, 1. 28-p. 145, l. 14. La traduction du De ente et essentia citée à la fin, d' abord littérale puis éloignée, dont il n' est pas clair si Hillel ne traduit que ce passage pour l' occasion ou veut dire qu' il en a traduit plus long ${ }^{113}$, diffère de la traduction complète que Juda de Rome a donnée plus tard ${ }^{114}$ de l' opuscule thomiste ${ }^{115}$. Il s' agit de préciser la relation asymétrique de l'existence véritable (absolue) et du devenir (ou existence par participation): s'il est vrai que toute existence (en devenir dans le temps) tient de l' existant (absolu), il ne l' est pas que ce dernier tienne du devenir.

\section{Bibliographie}

\section{Manuscrits consultés}

Munich, Bayerische Staatsbibliothek, hebr. 120

Oxford, Bodleian Library, Michael 335 [(olim 82) = catalogue Neubauer 1318]

Paris, Bibliothèque nationale de France,

hébr. 704

hébr. 706

112 Thomas d'Aquin, De ente et essentia, éd. Baur: Quia parvus error in principio magnus est in fine, secundum philosophum in I Caeli et mundi, ens autem et essentia sunt quae primo intellectu concipiuntur, ut dicit Avicenna in principio suae Metaphysicae, ideo ne ex eorum ignorantia errare contingat, ad horum difficultatem aperiendam dicendum est quid nomine essentiae et entis significetur et quomodo in diversis inveniatur.

113 Ni l'éd. Sermoneta des Tagmuley ha-nefeš ni celle qu' en ont donnée Schwartz-Fidora ne signalent le De ente et essentia parmi les textes qu'y cite Hillel de Vérone.

114 Sermoneta 1965, p. 20-21 et n. 41, l' estime né en 1292 (Zunz d' après le témoignage d'Emmanuel de Rome) ou «un peu plus tôt» en raison de l'influence qu'il a reçue des écrits d' Albert le Grand.

115 Éd. Sermoneta 1977 (1995), p. 19o, l. 1-7. - Juda Romano n' a donc pas été le premier, comme le pensait Sermoneta d'après son titre, à traduire en hébreu l' ouvrage de Thomas et qu'il ait suivi sur ce point aussi l' essai au moins partiel de Hillel, son devancier déjà dans la traduction du Liber de causis, est à prendre en compte dans la compréhension de ses propres intentions. - Steinschneider, dans Halberstamm, éd. cit., f. מאv, n. [2], croyait qu' il s' agissait là des [Theoremata] de esse et essentia de Gilles de Rome. 
hébr. 972

hébr. 1111

Rome, Bibl. Casanatense

200

2834 (catalogue Sacerdote 201)

\section{Sources primaires}

Al-Fārābī, Kitāb as-suyāsa al-madaniyya, al mulaqqab bi-mabād'i al-mawğūdāt [Livre du régime politique, dit Livre des principes des étants], éd. F.N. Najjar, Beyrouth, Dār al-mašriq, $1993^{2}$.

Al-Fārābī [éd. et trad. esp.], Al-Fârâbî, Obras filosófico-políticas, éd. et trad. esp. R. Ramón Guerrero, Madrid, csic-Editorial Debate, 1992.

Al-Fārābī [trad. hébraïque médiévale], Sefer ha-hathalot (Livre des principes), éd. Z. Filipowski, Sefer ha-asif, Leipzig, [pour] K.F. Köhler [1849]; réimpr. en Israël, 1969/1970, p. 1-64.

Al-Ghazālī, Logica et philosophia Algazelis Arabis, trad. Dominicus Gundissalinus, Venise, P. Liechtenstein, 1506.

Albert le Grand, De causis et processu universitatis a prima causa, éd. W. Fauser, Münster, Aschendorff, 1993.

Aristote, Metaphysica lib. I-XIV, recensio et translatio Guillelmi de Moerbeka. Praefatio, Wilhelmvon Moerbekes Übersetzung der aristotelischen Metaphysik, éd. G. VuilleminDiem, Leiden / Boston, Brill, 1995.

Aristote, Métaphysique, trad. française J. Tricot, Paris, Vrin 1933, réimpr. 1991.

Aristote, Physique, trad. J. Barthélemy-Saint-Hilaire, Paris, Librairie philosophique de Ladrange / A. Durand, libraire, 2 vol., 1862.

Avicenne, Canon, trad. lat. Gérard de Crémone revue par Andrea Alpago, Venise, apud Juntas, 1608 .

Avicenne, Poème sur la médecine, trad. lat. revue par Andrea Alpago, Cantica Avicennae, Wittenberg, haeredes G. Rhau, 1562.

Gilbert de la Porrée (Ps.), Liber sex principiorum, dans Porphyrii Isagoge translatio Boethii et anonymi fragmentum vulgo vocatum Liber sex principiorum, éd. L. MinioPaluello, B.G. Dod (collab.), Bruges / Paris, Desclée de Brouwer, 1966.

Gilles de Rome, Expositio super auctorem de causis Alfarabii, Venise, J. Zoppinus, $155^{\circ}$.

Henri de Gand (Ps.), Quaestiones in Librum de causis, éd. J.P. Zwaenepoel, Louvain / Paris, Publications Universitaires / B. Nauwelaerts, 1974.

Hillel de Vérone, Sefer tagmuley ha-nefeš [Les rétributions de l'âme]:

Hillel de Vérone, Sefer tagmuley ha-nefeš, éd. S.Z.H. Halberstamm, intr. M. Steinschneider, Lyck, M'kize Nirdamim, 1874.

Hillel de Vérone, Hillel ben Shemu'el of Verona, Sefer Tagmule ha-nefesh (Book of the 
Rewards of the Soul), éd. G.B. Sermoneta, Jérusalem, The Israel Academy of Sciences and Humanities, 1981.

Hillel de Vérone, Hillel von Verona, Über die Vollendung der Seele. Hebräisch-Deutsch, éd. Y. Schwartz, trad. A. Fidora, Fribourg-en-Brisgau, Herder, 2009.

Liber de causis-Die pseudo-aristotelische Schrift Über das reine Gute bekannt unter dem Namen Liber de causis, éd. O. Bardenhewer, Fribourg-en-Brisgau, Herder, 1882 [réimpr. Francfort-sur-le-Main, Minerva, s. d.]

Liber de causis — «Le Liber de causis. Édition établie à l'aide de go manuscrits avec introduction et notes», éd. A. Pattin, dans Tijdschrift voor filosofie, 28(1966), p. 90-203; réimpr. dans A. Pattin, Miscellanea, t. I, Leuven, Bibliotheek van de Faculteit Godgeleerheid, 200o, p. 74-187.

Liber de causis (trad. française) - P. Magnard, Olivier Boulnois, B. Pinchard, J.-L. Solère, La demeure de l'être. Autour d'un anonyme. Étude et traduction du Liber de causis, Paris, Vrin, 199o.

Liber de causis (éd. hébr.)—see Rothschild (2013c).

Moïse Maïmonide, Le guide des égarés, traité de théologie et de philosophie par Moïs ben Maimoun dit Maïmonide, trad. S. Munk, Paris, A. Franck, 3 volumes, 1856-1866 [réimpr. Paris, Maisonneuve et Larose, 1970].

Siger de Brabant, Quaestiones super Librum de causis, éd. A. Marlasca, Louvain / Paris, B. Nauwelaerts / Publications Universitaires, 1972.

Thomas d'Aquin, De ente et essentia, éd. L. Baur, Münster, Aschendorff, $1933^{2}$.

Thomas d'Aquin, De ente et essentia, éd. Commissio Leonina, in Sancti Thomae de Aquino Opera omnia, t. XLIII, Roma, Editori di San Tommaso, 1976.

Thomas d'Aquin, De ente et essentia [trad. hébraïque médiévale de Juda Romano] see Sermoneta 1977 (1995).

Thomas d'Aquin, Super Librum de causis expositio, éd. H.D. Saffrey, Fribourg / Louvain, Éditions philosophiques / E. Nauwelaerts, 1954 [réimpr. Paris, Vrin, 2002].

Zerahiyah b. Šealti’el Ḥen, Lettres, éd. R. Kirchheim, dans Oṣar neḥmad (2), 1857, p. 124143.

\section{Sources secondaires}

Bardenhewer, O. (1882) voir Liber de causis - Die pseudo-aristotelische Schrift.

D’Ancona, C. (1992a), «Philosophus in libro De Causis. La recezione del Liber de causis come opera aristotelica nei commenti di Ruggero Bacone, dello ps. Enrico di Gand e dello ps. Adamo di Bocfeld», dans Documenti e studi sulla tradizione filosofica medievale 3,1992 , p. 611-649.

D’Ancona, C. (1992b), «Saint Thomas lecteur du Liber de causis. Bilan des recherches contemporaines concernant le De causis et analyse de l'interprétation thomiste», dans Revue thomiste 92, p. 785-817.

D’Ancona, C. (1995), Recherches sur le Liber de causis, Paris, Vrin. 
Goldblum, I. (1894), Mi-ginezey Yiśra’el be-Fa'riz [Extraits des manuscrits hébreux de Paris], t. I, Vienne, M. Qnopflemakher.

Leicht, R. (2013), «Miracles for the Sake of the Master of Reason. Hillel ben Samuel of Verona's Legendary Account of the Maimonidean Controversy», dans Micrologus 21, p. 579-598.

Libera, A. de (1990), «Albert le Grand et Thomas d'Aquin interprètes du Liber de causis », Revue des sciences philosophiques et théologiques 74/3, p. 347-377.

May, R.A., Beit-Arié, M. (1994), Catalogue of the Hebrew Manuscripts in the Bodleian Library. Supplement of Addenda and Corrigenda to Vol. I, Oxford, Clarendon Press.

Möbuß, S. (1991), Die Intellektlehre des Levi ben Gerson in ihrer Beziehung zur christlichen Scholastik, Frankfurt, P. Lang.

Munk, S. (1859), Mélanges de philosophie juive et arabe, Paris, A. Franck.

Neubauer, A. (1886), Catalogue of the Hebrew Manuscripts in the Bodleian Library and in the College Libraries of Oxford, t. I, Oxford, Clarendon Press.

Pinès, Sh. (1967), Scholasticism after Thomas Aquinas and the Teachings of Hasdai Crescas and his Predecessors, Jérusalem, The Israel Academy of Sciences and Humanities.

Robert, A. (2014), «Dino del Garbo et le pouvoir de l'imagination sur le corps», dans Archives d'histoire doctrinale et littéraire du moyen âge 81, p. 139-195.

Rothschild, J.-P. (1994), «Les traductions du Livre des causes et leurs copies», dans Revue d'histoire des textes 24, p. 393-484.

Rothschild, J.-P. (2013a), «Traductions refaites et traductions révisées», dans R. Fontaine, G. Freudenthal (éds), Latin-into-Hebrew. Texts and Studies, t. I, Studies, LeydeBoston, p. 391-420.

Rothschild, J.-P. (2013b), «Le Livre des causes du latin à l'hébreu: textes, problèmes, réception», dans A. Fidora, H. Hames, Y. Schwartz (éds), Latin-into-Hebrew: Texts and Studies, t. II, Texts in Contexts, Leyde-Boston, Brill, p. 47-84.

Rothschild, J.-P. (2013c), «Les traductions hébraïques du Livre des causes latin. Édition synoptique», dans A. Fidora, H. Hames, Y. Schwartz (éds), Latin-into-Hebrew: Texts and Studies, t. II, Texts in Contexts, Leyde-Boston, Brill, p. 289-367.

Rothschild, J.-P. (2015), «Quelques philosophes juifs du Moyen Âge tardif, traducteurs ou lecteurs de saint Thomas d'Aquin », dans E.H. Füllenbach, G. Miletto (éds), Dominikaner und Juden. Personen, Konflikte und Perspektiven vom 13. bis zum 20. Jahrhundert, Berlin-New York, de Gruyter, p. 25-63.

Rothschild, J.-P. (2018), Moïse b. Sabbataï, lecteur juif du Livre des causes et adversaire de la kabbale, en Italie, vers 1340, Turnhout, Brepols.

Sadik, Sh. (2013), «Le choix moral dans la pensée de Rabbi Hillel de Vérone», dans Freiburger Zeitschrift für Philosophie und Theologie 6o/2, p. 292-314.

Schwartz, Fidora (2009) voir Hillel de Vérone, Über die Vollendung.

Sermoneta, G.B. (1962), R. Hillel b. Šemu'el b. Eli'ezer mi-Weyronah u-mišnato ha-pilosofit 
[R. Hillel b. Samuel b. Éliézer de Vérone et sa doctrine philosophique], thèse de doctorat de l' Université hébraïque de Jérusalem, [5]722 [/1961/2].

Sermoneta, G.B. (1965), «La dottrina dell' intelletto e la 'fede filosofica' di Jehudàh e Immanuel Romano », dans Studi medievali 6/2, p. 3-78.

Sermoneta, G.B. (1972; 2007), «Hillel ben Samuel», dans Encyclopedia Judaica ${ }^{1}$, Jérusalem, Keter, 1972, t. VIII, col. 488-49o; Encyclopedia Judaica ${ }^{2}$, Detroit, MacmillanKeter, t. IX, p. 113-115.

Sermoneta, G.B. (1974), « Mappolet ha-mal'akhim' [La chute des anges] », dans S. Pinès (éd.), Sefer zikkaron le-Ya'aqob Pridman z"l [Mémorial Y. Friedmann], Jérusalem, HaUnibersițah ha-'ibrit, Ha-Makhon le-mad'ey ha-yahadut, p. 155-203.

Sermoneta, G.B. (1977; 1995), «Ma'amar ha-nimșah we-ha-meșiut. Sancti Thomae de Aquino Opusculum de ente et essentia a Rabbi Jehudàh ben Mosèh ben Dani'èl Romano primum hebraice redditum... », dans A.Z. Bar-On(éd.), Mibhar țeqsțim pilosofiim mi-Parmenides 'ad yameynu [Choix de textes philosophiques de Parménide à nos jours], Jérusalem, s. n., 1977; rééd. ibid., 1995, p. 184-214.

Sirat, C., Klein-Braslavy, S., Weijers, O. (éds) (2003), Les méthodes de travail de Gersonide et le maniement du savoir chez les scolastiques, Paris, Vrin.

Steinschneider, M.(1852-186o) Catalogus librorum hebraeorum in bibliotheca Bodleiana, Berlin, A. Friedländer.

Steinschneider, M. (1863), Hebräische Biblbiographie 6.

Steinschneider, M. (1874), Hebräische Bibliographie 14, [c.r. de Hillel b. Samuel, Sefertagmuley ha-nefeš, Lyck, M'kize Nirdamim, 1874].

Steinschneider, M. $\left(1893 ; 1956^{2}\right)$, Die hebräischen Übersetzungen des Mittelalters und die Juden als Dolmetscher, Berlin, Bibliographisches Bureau; réimpr. Graz, Akademische Druck- und Verlaganstalt.

Taylor, R.C. (1983), «The Liber de causis: A Preliminary List of Extant Mss », dans Bulletin de Philosophie Médiévale 25, p. 63-84.

Vogelstein, H., Rieger, P. (1896), Geschichte derJuden in Rom, t. I, Berlin, Mayer \& Müller. Zonta, M. (1996), La filosofia antica nel medioevo ebreo, Brescia, Paideia.

Zonta, M. (2011), «Medieval Hebrew Translations of Philosophical and Scientific Texts: a Chronological Table», dans G. Freudenthal (éd.), Science in Medieval Jewish Cultures, Cambridge, Cambridge University Press, p. 17-73. 